
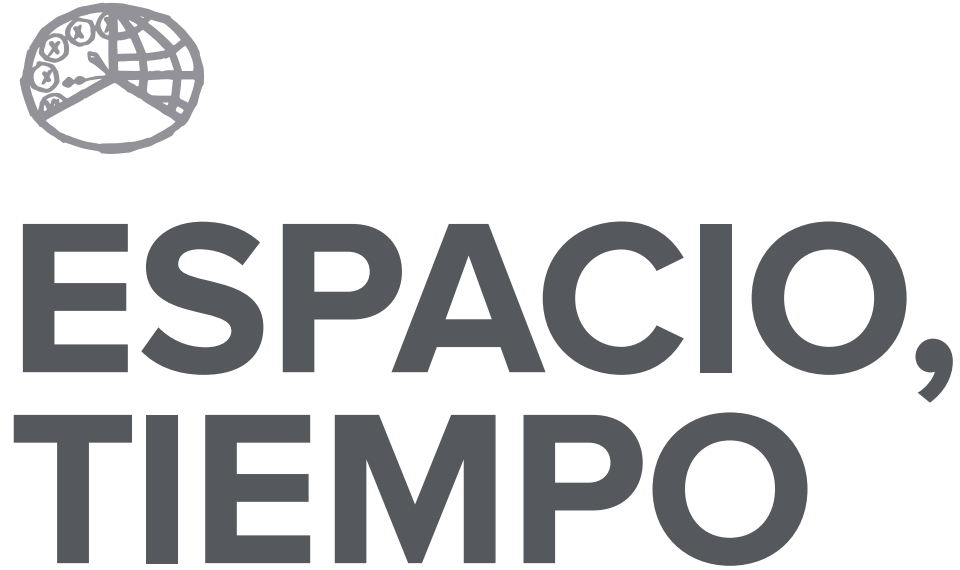

AÑO 2020

ISSN 0214-9745

E-ISSN 2340-1362
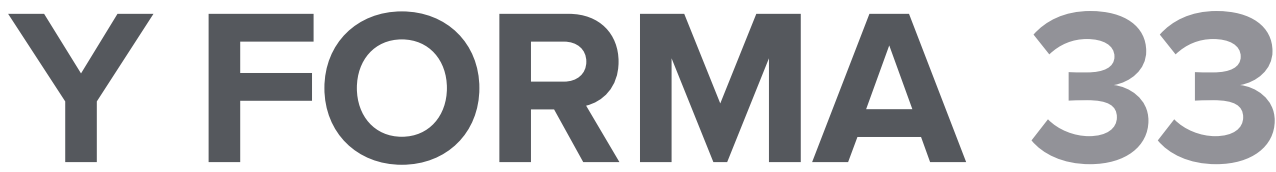

SERIE III HISTORIA MEDIEVAL

REVISTA DE LA FACULTAD DE GEOGRAFÍA E HISTORIA 



\section{ARTÍCULOS · ARTICLES}





\title{
LAS INSCRIPCIONES MEDIEVALES \\ DEL CLAUSTRO DE LA \\ CATEDRAL DE RODA DE ISÁBENA \\ (HUESCA). APROXIMACIÓN \\ A SU TALLER LAPIDARIO
}

\section{THE MEDIEVAL INSCRIPTIONS OF THE CLOISTER OF THE CATHEDRAL OF RODA DE ISÁBENA (HUESCA). AN INITIAL LOOK AT ITS LAPIDARY WORKSHOP}

\author{
María Encarnación Martín López
}

Recepción: 2020/01/10 · Comunicación de observaciones de evaluadores: 2020/03/03 .

Aceptación: 2020/03/06

DOI: http://dx.doi.org/10.5944/etfiii.33.2020.26349

\section{Resumen}

El conjunto de inscripciones funerarias de la catedral de Roda constituye con sus 225 letreros el obituario en piedra más importante conocido. El objeto de este artículo es presentar los inicios de una investigación monográfica del conjunto. El taller comienza su actividad entre I200-I230 para finalizar en últimas décadas del XIV. Se determinan las distintas etapas del taller epigráfico, así como las principales manos que intervienen en cada etapa, con especial relieve sobre la grafía del maestro de Roda. Estudiar su génesis, la forma y evolución de sus grafías es la metodología a seguir en orden a poner de relieve su valor historiográfico.

\section{Palabras clave}

Obituario; Epigrafía; taller epigráfico; scriptorium; liturgia; escritura gótica.

\section{Abstract}

The epigraphic collection of the cathedral of Roda with its 225 signs makes up the most important stone obituary known. The purpose of this article is to present the initial results of a monographic research of the whole complex. The workshop

1. Universidad de León. C.e.: memarl@unileon.es 
begins its activity between I200-I230 to end in the last decades of the fourteenth century. The different stages of the epigraphic workshop will be established as well as the main cutters' hands involved in each stage, with special emphasis on the script of the Master of Roda. In order to highlight its historical importance, the methodology adopted will include the study of the genesis of the various scripts, as well as their form and evolution.

\section{Keywords}

Obituary; Epigraphy; Epigraphic Workshop; Scriptorium; Liturgy; Gothic Scripture. 
La catedral de San Vicente de Roda de Isábena (Huesca) posee uno de los conjuntos epigráficos más importantes de la Península y de Europa. La particularidad y relevancia de este centro se debe al elevado número, unas 225 inscripciones ${ }^{2}$, todas ellas epitafios necrológicos. Este artículo es introductorio a un estudio exhaustivo y completo del conjunto epigráfico que próximamente se publicará. Las primeras reflexiones sobre el taller epigráfico se pondrán de relieve en este artículo. Partimos del trabajo de Durán $\mathrm{Gudiol}^{3}$, fundamental hasta el momento, pero que dados los avances sobre paleografía epigráfica de los últimos años precisa una revisión. Trataremos el porqué de dicho conjunto, así como las etapas de ejecución y las características gráficas de sus principales lapicidas.

\section{INTRODUCCIÓN}

Todas las inscripciones se localizan en el claustro, a lo largo de sus cuatro pandas, en los sillares en los muros, en los intradoses de los arcos, los cimacios y ábacos. La elección de este espacio no es casual. El claustro es el lugar propio de meditación para la comunidad, a la vez que espacio de liturgia y oración, que, según el simbolismo medieval, evoca el jardín del Edén. El epígrafe es por su naturaleza una manifestación pública de cualquier mensaje y un lugar físico del recuerdo, los trazos visibles y legibles son la conmemoración, la memoria de la memoria ${ }^{4}$. Para este conjunto Durán Gudiol utilizó la expresión de Necrologium pétreo5, pues, como en los libros, en ellos encontramos nombres de difuntos, con

2. De las 225 , una, la correspondiente a los obispos, está en el interior del templo. De las 224 restantes, halladas en el claustro, se han editado 204 (de éstas 7 ya han desaparecido) y 21 permanecen inéditas. Actualmente se está realizando un estudio del conjunto rotense por Daniel Vega, responsable del volumen correspondiente a la provincia de Huesca en la colección Corpus Inscriptionum Hispaniae Mediaevalium. Esta colección cuenta ya con 6 volúmenes publicados: Burgos (2015) Salamanca (2016) Valladolid (2017) Guadalajara (2018) Cantabria (2019) La Rioja (2020).

3. Es inevitable la referencia a su trabajo, por su calidad, a pesar de las precisiones que hagamos. Los números de las inscripciones hacen alusión a su apéndice epigráfico.

4. GIOVE MARChIOLI, Nicoletta, «L' impossibilità di essere autonoma donne e famiglia nelle fonti epigrafiche tardomedievali», Archeologia Medievale, XXXVIII, 2011, p. 20. Hago propias las palabras de J. de Santiago recordando las primeras premisas sobre el fin de la epigrafía expuestas ya por Gómez Moreno en 1953 como «composición literaria para conmemorar un hecho en condiciones monumentales», añadiendo que «publicidad solemnidad y perduración la caracterizan y éstos son los requisitos exigibles para entrar en el noble acervo de la Epigrafía», GómEz MORENO, Manuel, Discurso de D. Manuel Gómez-Moreno y Martínez, en Navascués y de Juan, Joaquín María, El concepto de la Epigrafía. Consideraciones sobre la necesidad de su ampliación, Madrid, Real Academia de la Historia, pp. 85-102, 1953, p. 93. Desde entonces la valoración de la importancia del elemento publicitario en la investigación epigráfica ha sido creciente, FaVreau, Robert, «Functions des inscriptions», en Etudes d'epigraphie medieval, Limoges, 1995 Pulim, pp. 155-205.; PetrucCI, Armando, La scrittura: ideologia e rappresentazione, Turín, 1986; SUsINI, «Le scritture esposte», en Lo spazio letterario di Roma antica. 2. La circolazione del testo, Roma, Salerno, 1989, pp. 271-305; ALföLDY, «Augusto e le iscrizioni: tradizione ed innovazione. La nascita dell'epigrafi a imperiale», Scienze dell'Antichità. Storia, Archeologia, Antropologia, 5, 1991, pp. 573-600; GARCíA LOBO, Vicente, Los medios de comunicación social en la Edad Media, 1991; DONATI, Epigrafia romana. La comunicazione nell'antichità, Bolonia, 2002 ; DeBIAIS, Vincent, Messages de pierre. La lecture des inscriptions dans la communication médiévale (XIII'-XIVe siècle), Turnhout, Brepols 2009.

5. DuRÁN GUDIOL, Antonio, «Las inscripciones medievales de la provincia de Huesca», en Estudios de Edad Media de la Corona de Aragón, 1967, p. 65. Con términos similares se refirió García Lobo a las inscripciones del claustro de Santo Domingo de Silos, obituario en piedra. García Lobo, Vicente, 1990, p. 88. 
la correspondiente referencia a las fechas de fallecimiento, por los cuales la comunidad debe hacer una conmemoración en el día del aniversario de su muerte. Esta idea puede aplicarse a conjuntos epigráficos como los constatados en San Juan de la Peña o Santo Domingo de Silos. El conjunto epigráfico necrológico de Roda es el más importante de la Península, superando al magnífico conjunto funerario del monasterio cisterciense de Alcobaça (Portugal) ${ }^{6}$. Estas inscripciones funerarias merecen una consideración especial, además, por las particularidades gráficas que hacen de ellas un conjunto original. No es posible realizar un estudio riguroso de este conjunto en un espacio tan pequeño como un artículo. Sirva éste como una aproximación de estudio al conocimiento del taller epigráfico, inicio, evolución y tiempos finales armonizados desde un eje que todo lo vertebra, como es la producción e intervención en el taller del, denominado por Duran Gudiol, maestro de Roda.

\section{I.1. EDICIONES DE LAS INSCRIPCIONES}

El primero en estudiar y publicar las inscripciones de Roda fue Joseph Gudiol, conservador del Museo Episcopal de Vich7 en el año 1907. Publica I75 inscripciones siguiendo el orden desde los arcos de la galería cercana a la entrada desde la iglesia seguidas por las arquerías de las otras alas y acabando por las halladas en los muros. La transcripción desarrolla las abreviaturas e indica el cambio de renglón en el epígrafe con una raya. Determinó su ejecución, las más antiguas, en el siglo XII. Las inscripciones de ese siglo, afirma Gudiol, forman encuadramientos, óbolos u hornacinas, algunas inscripciones tienen letras coloreadas en azul, bermejo o negro.

En I967 Durán Gudiol publicó el corpus medieval de la provincia de Huesca. Se trataba del primer corpus de inscripciones que se editaba en España con un total de 269 inscripciones procedentes de los principales centros eclesiásticos de la provincia, esto es, el monasterio de San Juan de la Peña, la catedral de Jaca, y la catedral de San Vicente de Roda de Isábena. Iba a ser la primera de una serie de ediciones epigráficas que tenían por objetivo dar a conocer la totalidad de los textos conservados, así como las lecturas propias y de otros autores anteriores. Desgraciadamente el proyecto se vio truncado tras esta primera edición que, aún hoy, seguimos considerando básica para conocer la epigrafía oscense ${ }^{8}$. El conjunto

6. Estudiado y publicado por BARROCA, Mario Jorge, Epigrafía medieval portuguesa, 862-1422, 2 vols., Lisboa, 2000.

7. GUdIOL, Joseph, «El necrologi de l'iglesia de Roda», en Anuari de l'institut d'estudis catalans, 1907, pp. 19-29. «Algunas pocas inscripciones mutiladas o en mal estado «o por estar tapades per les construccions que s' han anat fent ab els segles en el claustre y ses dependencies, essent la principal causa de la mutilació dels epigrafs la abominable ocurrencia que va tenirse, de tancar els archs de les galeries claustrals fins arran dels abachs de les columnas». Todas las inscripciones del claustro son necrológicas excepto la que se haya en la pared próxima a la sacristía: Non chorus clamor erit, ubi clerus regula dixit.

8. Durán Gudiol ha tenido en cuenta en su edición las normas publicadas por el CSIC, Normas de transcripción y edición de textos y documentos, Madrid 1944, pp.39-41. Hoy en día la edición de inscripciones ha evolucionado y madurado 
publicado por Durán Gudiol relativo a la catedral de Roda es de i9i inscripciones. Su edición identificaba la mano de un maestro, el de Roda, al que atribuye I2o de ellas, siendo esta actividad realmente extraordinaria.

\section{I.2. LAS INSCRIPCIONES DE RODA}

El gobierno de Aragón inició en 2017 una nueva intervención en el claustro para restaurar y limpiar sus muros. La intervención permitió recuperar algunos epígrafes tapados por el mortero, quedando las piezas limpias. Se descubren algunos fragmentos de inscripciones reutilizadas en las distintas fases de construcción del claustro y que permanecían ocultas. Todo ello ha elevado el número de piezas que viera Gudiol. Las tareas de restauración no solo han afectado a las piezas en mal estado como las ubicadas en la galería norte y este, sino también a la restauración del color originario de las situadas en la sala capitular y que permite conocer cómo era originariamente este magnífico conjunto.

Durán Gudiol conoció el conjunto rotense en unas condiciones muy distintas a las actuales, pero supo determinar con precisión sus peculiaridades y su valor. Edita I9I inscripciones, un número que hoy gracias a las actuaciones de limpieza y restauración de los últimos años se han incrementado a 225. Este obituario en piedra por su calidad y cantidad es el más importante de .la Península Ibérica junto al del monasterio cisterciense de Alcobaça. Le sigue el obituario del monasterio benedictino de Silos con 75 inscripciones, y mucho más lejos los monasterios de San Miguel de Escalada ${ }^{9}$, San Juan de la Peña con una treintena y editadas por el propio Gudiol, Santa Cristina de Ribas de $\mathrm{Sil}^{\mathrm{Io}}$, Santiago de Peñalba ${ }^{\mathrm{II}}$.

Este notable conjunto epigráfico, no obstante, fue mayor. Las diferentes reformas sufridas por el claustro catedralicio llevaron al desastre a un número indeterminado de epígrafes. Algunos testimonios de los avatares sufridos los conocemos; piezas fragmentadas por el desmantelamiento son reaprovechadas como material de construcción de sus propios muros. Algunos se ponen al revés, al perder su función original. Otras se retallan para ser adaptadas como piezas de apoyo, ábacos, cimacios en la arquería. Otro factor de deterioro del conjunto

\footnotetext{
su propio método y se está preparando la colección completa de la edad media epigráfica, así como su estudio crítico por Daniel Vega, que será editado en el volumen 8 de CIHM (Corpus Inscriptionum Hispaniae Mediaevalium) en el marco del proyecto de investigación I+D HAR2016-76310-R bajo los auspicios del Ministerio de Economía Industria y Competitividad y de los fondos europeos FEDER.

9. Cf. García Lobo, Vicente, Las inscripciones de San Miguel de Escalada, El Albir, Barcelona 1982; una nueva edición revisada Martín LóPez, M.E., «Las inscripciones de San Miguel de Escalada. Nueva lectura», en San Miguel de Escalada (913-2013), Universidad de León, 2013.

10. Inscripciones estudiadas por García Fernández, Patricio, «La memoria epigráfica del monasterio de Santa Cristina de Ribas de Sil, sus inscripciones medievales», en Boletín Auriense, 33 , 2003, pp. 185-208.

11. Estudiadas por García Morilla, A., «De la funcionalidad en las inscripciones. El caso del monasterio de Santiago de Peñalba (León)», en San Miguel de Escalada (913-2013), León 2013, pp. 273-293.
} 
es la climatología extrema que sufre el territorio de la Ribagorza y que afecta de diferente forma según la ubicación de los epígrafes. La intervención ha contribuido, así mismo, a fijar aquellas piezas afectadas por la erosión del viento y las lluvias y las duras heladas. En definitiva, el conjunto epigráfico rotense presenta una conservación muy variable. La recuperación de los colores originales en parte de las piezas es uno de los logros obtenidos que permite acercarnos a su realidad visual y estética medieval.

\section{I.3. LA DATACIÓN DE LAS INSCRIPCIONES}

Una de las cuestiones a revisar es la datación de las inscripciones y la cronología dada a la actividad del taller epigráfico. Durán Gudiol establece una relación entre el inicio de la actividad del taller epigráfico con la redacción y envío del Necrologio rotense a Pamplona. A partir de las lápidas que indican el año de defunción del titular establece que el envío se realizó después del año I2I9 y antes de I232, ya que figura en el obituario navarro el canónigo Bernardo (+I2I9, $\mathrm{n}^{\circ} 236$ ) y no el prior Bernardo (+I232, $\left.\mathrm{n}^{\mathrm{O}} 243\right)$, ni los sucesivos años ${ }^{\mathrm{I2}}$. Esta conclusión es válida. Siguiendo las fechas de año de las inscripciones asegura que el necrologio pétreo no puede ser anterior al año I225, fecha en que se pintó la inscripción de la viga que señala el sepulcro de siete obispos $\left(n^{\circ} 79\right)$.

Distinto es dar como válidas las fechas de las inscripciones para determinar su cronología. El año de la ejecución de la anotación en piedra no tiene que ser necesariamente correlativo al óbito. Esta suele ser inmediata en los documentos necrologios, sin embargo, la ejecución de los letreros epigráficos se produce en un tiempo posterior con márgenes temporales muy diversos, meses o años. Un ejemplo sería la anotación de la defunción del canónigo Benedicto ${ }^{\mathrm{I} 3}$. El óbito se produce en I25I, no obstante, el letrero epigráfico se ejecuta décadas después, a finales de siglo. Esta realidad se repite de forma continuada lo que muestra el modus operandi del obituario cuya ejecución tendría lugar en campañas de actualización, cada Io o 20 años.

12. DURÁN GUDIOL, «Las inscripciones», p. 70.

13. DURÁN GUdIOL, «Las inscripciones», p. 72, $\mathrm{n}^{\circ} 113$. 


\section{CONTEXTO SOCIOCULTURAL}

\section{II.1. EL CULTO A LOS DIFUNTOS EN LAS CANÓNICAS AGUSTINIANAS}

Todas las comunidades religiosas establecen en sus constituciones y en la orden artículos o normas que regulan el trato a los hermanos difuntos, esto es, cómo actuar, en el velatorio y entierro, así como las oraciones y ritos en su memoria. Las congregaciones agustinianas, como otras, ponían todo su esmero en velar al difunto, en su sepultura, así como en la oración por su alma. El mismo San Agustín dedica un tratado a la piedad con los difuntos. En él advierta que lo que ayuda al muerto y a su alma es el afecto de los que le recuerdan y le encomiendan ${ }^{14}$, y le ofrezcan cada día oraciones en sufragio. Sepultado el hermano y cumplidos los requisitos del entierro la comunidad se reúne en la sala capitular donde se cumplirán los deberes para con el difunto, plegarias y sufragios. Una de ellas es el responso ante el féretro donde se canta y se recita según el ritual, en latín, el canto «libera me, domine, de morte eterna in die illa tremenda», una oración que se perpetua en muchos casos en una filacteria central sobre el túmulo sepulcral.

En la conmemoración de todos los difuntos de la Orden, y los otros aniversarios de difuntos de la Orden señalados en las Constituciones y en la epacta o calendario propio, concluida la misa cantada, se hacían las cinco estaciones por la iglesia o, en algunos sitios por el claustro. Se abría la procesión encabezada por la cruz alzada y los acólitos con los ciriales y el turiferario. Les seguían todos los religiosos de la comunidad con hábito coral y velas encendidas en la mano, seguidos del preste y sus ministros. En cada esquina se detenía la procesión para cantar un responso con su oración respectiva. La quinta se hacía ante el túmulo o catafalco, que se hallaba junto a las gradas de presbiterio ${ }^{15}$.

\section{II.2. CONTEXTO DEL NACIMIENTO DEL NECROLOGIO EN PIEDRA. DEL DOCUMENTO A LA INSCRIPCIÓN}

El libro obituario es un libro conmemorativo común para las comunidades monásticas y catedralicias cuya finalidad es anotar en un calendario el día y mes de defunción de miembros propios o de otras comunidades hermanas ${ }^{16}$. Es la creencia

14. San Agustín, Tratado sobre la piedad con los difuntos, p.7, citado en CARMOnA Moreno, Félix, «Los difuntos en las Constituciones y Rituales de los agustinos. Lugar de enterramiento y libros de difuntos», en El mundo de los difuntos: culto, cofradías y tradiciones, San Lorenzo del Escorial 2014, pp. 681-698. p. 683.

15. Cf. Carmona Moreno, «Los difuntos en las Constituciones» y Rituales de los agustinos, p. 692

16. No todos los necrologios en piedra se vinculan a estos libros. Tenemos las inscripciones de Sant Pau de Camp en Barcelona cuyo contenido se vincula directamente a las mandas testamentarias que ordenan la fundación de aniversarios. 
en la eficacia de la oración la que explica el origen de los obituarios en la Edad Media, necesaria para la salvación del alma, donde entra en juego la solidaridad entre vivos y difuntos ${ }^{17}$. Tiene su antecedente, no obstante, en la celebración de los aniversarios de los mártires que, a mediados del siglo $\mathrm{V}$, se anotaban en los Fastos Romanos de Polemius Silvius para recordar el día de su muerte ${ }^{\mathrm{I}}$. En los dípticos encerados que se colocaban en el altar para la liturgia de la misa se escribían los nombres de santos, obispos, y difuntos. El número creciente de nombres obligó a su regulación en el Concilio de Mérida de 666, a partir del cual se buscan formulaciones más breves, y se determina que cada parroquia lea los nombres de los propios $^{19}$. Recitar los nombres de los difuntos en voz alta se convierte en una recomendación, y en una obra de misericordia. En el siglo IX empiezan a escribirse los nombres de los difuntos en los márgenes de los sacramentarios ${ }^{20} \mathrm{En}$ el siglo X los nombres se escribían en las cartas de confraternidad, tanto religiosos como laicos. El laico, al entrar en fraternitas con el monasterio, entrega parte de sus bienes terrenales para así lograr una oración por su alma ${ }^{21}$. Ahora bien, estas «comunidades de oración» no siempre residen en el mismo lugar, sobre todo si se trata de fraternidades monásticas. Se crean los rotuli mortuorum, y las cartas mortuorias que hacen llegar la noticia de la muerte de los miembros de la comunidad $^{22}$. Paralelamente a estos documentos y libros nace en el siglo IX, tanto en comunidades monásticas como clericales, el uso de conmemorar en capítulo los difuntos y su aniversario, dando origen a los necrologios, listas de difuntos ordenadas en el calendario romano para servir de conmemoración cotidiana de

Son estas inscripciones propias y desarrolladas en la baja edad media a partir del siglo XIV. Cf. SANTIAGo, Javier de, «Oraciones por la salvación del alma. El obituario en piedra del monasterio de Sant Pau de Camp de Barcelona», en Anuario de Estudios medievales, 46 /2, 2016, pp. 939-973.

17. HeRrero, Mauricio, «La muerte en los obituarios medievales», en IX Jornadas científicas sobre Documentación: la muerte y sus testimonios escritos, Universidad Complutense, Madrid 2011, p. 201; LeMAîTRE, J.L., "Un livre vivant, l'obituaire», en GLENISSON, J (dir.), Le livre au Moyen Âge. París: CNRS, 1988, pp. 92-94; MITRE, E., «El sentido medieval de la muerte», en Anuario de Estudios Medievales, 16, 1986, pp. 621-63.

18. LeClercQ, H., « Obituaire », en Dictionnaire d'Archéologie Chrétien et Liturgie, 12-2. París, 1936, cols. 1834-1857.

19. Recogido por M. Herrero de la obra a su vez citada de TRENCHS OdenA, E., «El necrologio-obituario de la catedral de Cuenca», en Anuario de Estudios Medievales, 12 (1982), p. 341.

20. De esta forma el oficiante no se olvidaba de recitar el nombre en la misa por tanto se anotaban junto a la fórmula del canon pertinente, Te igitur, o Vere dignum est. Cf. Herrero, p. 204, que toma a su vez de Molinier, A., Les obituaires français au Moyen Âge. París, 1890, p. 17.

21. Desde el siglo $X$ se hace frecuente la donación pro anima, que implica la entrega de bienes de laicos a monasterios a cambio de poder asegurarse las oraciones post mortem, coincidente con el movimiento de sufragios que potencia Cluny. Una revisión es realizada por el ya clásico estudioso de este tema MatToso, José (dir.), O reino dos mortos na Idade Media, Lisboa 1996, donde publica dos artículos sobre el culto a los difuntos. IOGNA PRATT, D., «Los muertos en la contabilidad eclesial de los monjes cluniacenses», en LITTLE L.K. y RosENWEIN B. (ed.), La Edad Media a debate, Madrid 2003, pp. 521-551. No disfrutaban, no obstante, de las mismas oraciones que se rezaban por los monjes de la comunidad. Cf. Herrero, p. 203; sobre la fraternitas el clásico estudio de Orlandis sigue siendo una referencia válida, que hallamos en uno de sus últimos trabajos, ORLANDIS, José, La vida en tiempos de los godos, Madrid 1991. Existe, además, una fraternidad económica no solo entre laicos y monasterios, sino también entre diferentes comunidades monásticas que comparten bienes como si fuera una sola.

22. Huyguebaert, N., Les documents nécrologiques, Turnhout, 1972, pp. 26-32. 
los difuntos ${ }^{23}$. Documentos de uso estrictamente litúrgico, aunque después se les añadieran otros datos de carácter económico, como las dotaciones para los aniversarios. Su transformación se produce en el siglo XIII, coincidiendo con el nacimiento de la idea de Purgatorio. Se determina en este periodo la diferencia entre necrologio y obituario. En el obituario se escribirán los nombres de los que fundan un aniversario ${ }^{24}$. Con la transformación del obituario se pasa del recitado de nombres a nuevas prácticas como las misas de difunto, los aniversarios, las capellanías. El nuevo tipo de noticias y anotaciones que reciben estos documentos, con altas de propiedades, pero también con bajas de éstas procediendo a tachar la anotación, harán dificultosa la consulta puramente litúrgica ${ }^{25}$.

Coincide en el tiempo, en el siglo XIII, una nueva práctica entre las canónicas y los monasterios: la trasportación de las anotaciones del obituario a soporte pétreo. De la disposición jurídica, donación o testamento, se pasa a la anotación en el obituario, para la organización administrativa. No conforme con ello se precisa una publicidad que tendrá dos vías: la vía litúrgica, que consiste en trasladar a piedra los nombres de difuntos del necrologio para su celebración; la vía administrativa que lleva a trasladar a piedra los contratos y mandas testamentarias para su debido cumplimiento, de ahí que se copien en inscripciones funerarias -epitafios necrológicos- dispuestas en los espacios litúrgicos funerarios, capillas y claustros ${ }^{26}$. Estos obituarios en piedra vienen determinados por un origen contractual, conceder bienes a cambio de oraciones, aunque el recuerdo por el difunto sigue siendo el objetivo principal. Es el caso del Epitaphium necrologicum de Guillermo de Bruguera. I293. (Crux) Anno D(omi)ni M CC XC Ill obiit G(uillermus) de Brugar/ia, $\mathrm{q}(\mathrm{u}) \mathrm{i}$ duo anniv(er)saria in die obit(us) sui hic constitu/it, unu(m) videlicet q(u)od detur in pane pauperib(us) $\mathrm{Ih}(\mathrm{es}) \mathrm{u}(\mathrm{s}) / \mathrm{Chr}(\mathrm{ist}) \mathrm{i}$, aliud pro pieta(n)cia co(n)ventui, $\mathrm{q}(\mathrm{u}) \mathrm{i}$ celebrent / et faciant solle(m)pnit(er) officium mortuoru(m) i(n) il/la die.

23. Sirve esta definición para las diferentes acepciones que reciben estos documentos: necrologios, obituarios, libros de aniversario, libros de distribución, etc. Se atribuye a Usuardo el ordenar las largas listas de difuntos en un calendario, anotando los nombres en el día correspondiente a su muerte. Cf. DuBols, Jacques, Les martyrologes du Moyen âge latin, Typologie des sources du Moyen Agen occidental, 26, Turnhout 1978, p. 46.

24. En el obituario el nombre del difunto a recordar y por el que se rezará no se registra en el libro por el hecho de pertenecer a una comunidad de oración o por su fama o por su bonhomía o por su generosidad, sino porque el difunto lo dispuso así antes de morir. Cf. HERRERO, p.207. La polémica diferencia entre necrologio y obituario arranca desde Huyguebaert quien sostiene la diferenciación entre el necrologio, de documento de uso litúrgico, y el obituario, documento de uso administrativo. Esta idea la rebate Lemaître quien considera el Necrologio el documento donde se anotan únicamente los nombres de difuntos de la comunidad y sus fraternitates, mientras que el obituario anota personas de fuera de la comunidad que solicitan un aniversario.

25. Al convertirse en libros, prácticamente, administrativos la lectura de estos documentos se dificulta. Las manos y grafías son diversas, muchas en cursiva. Sobre estas dificultades vid. Herrero Jiménez, Mauricio, Colección documental del archivo de la catedral de León. X. Los obituarios de la catedral de León, León 1994; Serna Serna, Sonia, Los obituarios de la catedral de Burgos, León 2007. Una clara transformación del necrologio a obituario lo tenemos en San Zoilo de Carrión, en el siglo XIII. Cf. REGLERO, «El necrologio-obituario de San Zoilo de Carrión», en Alma Littera, Valladolid 2014, pp. 525-533. Una relación de las ediciones en los últimos años sobre estos documentos lo recoge PoNs CORTES, A., «Necrologios y obituarios medievales en la Península Ibérica y su utilización como fuente para la historia de la arquitectura», en Medievalia. Revista d'estudis medievals, 20/1 2017, pp. 197-223.

26. SANTIAGO, J. de, «Oraciones por la salvación del alma», p. 944. 
Que anniv(er)saria assigna(n)tur sup(er) ospicium / R(aimundi) de Colpeyeres et Math(e)i de Collo, Michaelis / de Collo, Bere(n)- garii Va(n)relli. Que(m) totu(m) honore(m) / ip(s)e emit a Petro de Capellatis et a Bere(n)gario, / fi lio suo, p(re)cio $\operatorname{triu}(\mathrm{m}) \mathrm{miliu}(\mathrm{m})$ solidorum (Crux $)^{27}$.

Otros epitafios necrológicos, como es el de Roda, realizan las funciones litúrgicas manteniendo el contenido en su forma original, siempre uniforme, sin variaciones. Se trata de una relación de difuntos anotados en la fecha de su muerte, sin anotaciones de tipo administrativo ${ }^{28}$. Daremos en denominarlo Necrologium, por su finalidad litúrgica y celebrativa para la oración por los difuntos establecida en la mayoría de las comunidades los lunes en vísperas ${ }^{29}$. El formulario es idéntico y homogéneo, en el documento/libro y en las inscripciones.

En definitiva, la creación de necrologios en piedra surge ante la transformación de los documentos necrologios en obituarios. La práctica de la liturgia de difuntos, afectada por el cambio recurre a un soporte público y permanente con finalidad celebrativa.

\section{EL NECROLOGIUM ROTENSE}

El necrologium de Roda en pergamino ha desaparecido. Se desconoce su contenido, así como las fechas de inicio y final de las anotaciones. Pero conocemos parte de su contenido gracias a las inscripciones y quizá ellas nos proporcionen algún dato a mayores sobre el documento perdido.

Del libro necrologio de la comunidad catedralicia nada queda salvo el propio traslado de su contenido a piedra. Sabemos que comienza a confeccionarse a finales del siglo XII pues la primera memoria es de 1944 ( ${ }^{\circ}$ I28) correspondiente al prior Ramón. Desde este año parece que las anotaciones en el libro son constantes hasta I334 última data del seglar Pedro de Torre ( ${ }^{\circ}$ I54). Las memorias necrológicas se iban anotando en el libro necrologio a medida que se producían las defunciones. Posteriormente se pasaban a la piedra por el lapicida pertinente. Ahora bien, el traslado a piedra es casi simultáneo en las primeras etapas de realización, distanciándose el espacio temporal entre la anotación en el libro y su transliteración a piedra medida que avanza el siglo y sobre todo en el siglo XIV.

27. Publicada por SANTIAgo, J. de, «Oraciones por la salvación del alma», p. 945. Este mismo autor reflexiona: Distinto es la intención de otras inscripciones funerarias que podemos confundir con la necrológicas pero que incluyen fórmulas referentes a la fundación de aniversarios o la realización de diversas donaciones a favor del monasterio a cambio de obtener ese fin, es decir el bien perpetuo de la oración por la salvación de su alma, parece el objetivo fundamental. A estas debemos denominarlas Fundationes aniversarii o Monumentum fundationis.

28. Huyghebaert, Les documents necrologiques, p. 42. De ahí que la denominación que diera Durán Gudiol al conjunto epigráfico de Roda como «necrologium» es más precisa que obituario.

29. Cf. García Lobo, Vicente, La colegiata de Santa Maria de Arbas, León 1990. 
Los canónigos rotenses tenían establecido un pacto de hermandad con la canónica de Santa María de Pamplona a la que enviaron copia de su obituario para que fuera incorporado en el necrologium de la seo navarra ${ }^{30}$, hecho que sucede antes del año I232 fecha de la última anotación en el obituario navarro ${ }^{31}$. Quizá esta fecha dista mucho del comienzo del propio obituario de Pamplona cuya confección data de I277, siendo sus últimas anotaciones en I28632. Una hipótesis que explicaría este desfase de cuarenta y cinco años del envío a la anotación apunta a la existencia de un obituario anterior a I277 y cuyo contenido es copiado en un nuevo obituario, el que hoy conocemos. Mientras, en Roda, el obituario comienza a ser esculpido en los sillares del claustro siguiendo el orden del libro. Veamos la relación de difuntos.

El obituario o necrologio en piedra nos ha transmitido la fecha de fallecimiento de personas de diferentes clases sociales, clérigos y laicos, hombres y mujeres, que mantuvieron una relación con la canónica. La mayoría corresponden a la jerarquía o dignidades catedralicias. Pero también figuran personajes ligados a la comunidad por medio de la fraternitas o familiaritas. Generalmente la identificación del personaje es sucinta, con solo el nombre, lo que indica que no es el carácter o la vanagloria lo que predomina33. Algunos nombres se repiten una y otra vez, Petrus, Bernardus, Arnaldus, Bertrandus, Iohannes. Esto es normal al tratarse de nombres comunes. Pero llama la atención un caso concreto que lleva nombre y apellido, Pedro de Turri, y que aparece en dos inscripciones ${ }^{34}$ en I322, enero 9, como camerarius rotensis, y en I334, abril, 25, simplemente con su nombre.

En las anotaciones predominan, naturalmente, los miembros de la comunidad rotense que suelen identificarse bajo sus diferentes cargos: canonicus, canonicus et sacerdos, canonicus et levita ( canonje no presbítero pero que tenía las ordenes menores) ${ }^{35}$, clericus et sacerdos, precentor (director del coro el que daba el tono en las comunidades obligadas al rezo de los oficios colectivos), prior claustri, archidiaconus ( dignidad eclesiástica en virtud de la que el que la posee era ayudante del prelado en los oficios divinos y era el primero entre los canónigos), sacrista (el encargado de la custodia de los objetos sagrados, era un oficio y una dignidad), camerarius

30. Gudiol advierte el error de interpretación por parte del editor del obituario Ubieto Arteta, cuando desarrolla la abreviatura RO como rationarius, cuando en realidad es rotensis. Cf. DURÁN GUDIOL, «Las inscripciones», p. 69.

31. Cf. DURÁn GUdıol, «Las inscripciones», p. 70.

32. La fecha de redacción dada por el propio Ubieto se basa en las fechas extremas que aparecen en los óbitos anotados. Confirma su teoría con la circunstancia de que tampoco se copia el día de fallecimiento de Jimeno López de Luna, prior que fue de la catedral hasta 1288.Cf. UBIETO ARTETA, Antonio, El obituario de la catedral de Pamplona, Instituto Príncipe de Viana, Pamplona 1954, p. 6.

33. Encontramos algunos apellidos, laicos de la zona o territorios limítrofes que posiblemente hayan fundado un aniversario o entregado sus bienes para ser enterrados en el claustro pero que no tenemos más evidencias que la aportada por el óbito de Berengario Marquesi que fundó una capellanía y un aniversario para su muerte acontecida en 1324; otras anotaciones son Raimundo de Puivert ( $n^{\circ} 84$ ), Bernardo de Porta Saloma fallecido en 1262 ( $n^{\circ} 88$ ) Pedro de la Touillada ( $\left.n^{\circ} 107\right)$, Guillermo de Calasanz $\left(n^{\circ} 135\right)$, Raimundo de Tora, Martin Galíndez ( $\left.{ }^{\circ} 145\right)$, Berengario de Lagnares $\left(n^{\circ} 168\right)$, Guillermo de Calle ( $\left.n^{\circ} 191\right)$, Gil de Cillis ( $\left.n^{\circ} 215\right)$. Los números corresponden a la edición de Duran Gudiol.

34. DURÁN GUDIOL, «Las inscripciones», nº 87 y 154.

35. GUDIOL, «El necrologi de l'iglesia de Roda», nota 20 
(canónigo encargado de la conservación de la casa comunal, administrador o mayordomo ${ }^{36}$. Debemos mencionar brevemente a los conversos, hombres que se habían entregado a la iglesia de Roda en edad avanzada o madura.

A la comunidad se suman los socii. Con este término se denomina a los participantes en las oraciones en la iglesia de Roda. Son personas que han ganado con sus méritos entrar en la confraternidad espiritual formada por los canónigos y beneficiarios de la iglesia ${ }^{37}$. José Gudiol lee la inscripción 94 que Antonio Durán no descifra. Gudiol lee Martinus Carascheri comunerius. Sería este un administrador de los bienes de la comunidad ${ }^{3}$. Llama la atención el epígrafe de Petrus carpentarius nostri et socius. Esta es una información interesante ya que nos da el nombre del carpintero de la obra catedralicia o maestro de obras. La inscripción es realizada durante el siglo XIII periodo de la construcción de ésta.

No tenemos tantas notificaciones sobre las dignidades que tan solo aparece la de Barrabés. Recordemos no obstante cuales son dichas dignidades: abad de Alaón, arcediano de Ribagorza, arcediano de Tierrantona, arcediano de Benasque, arcediano de Pallars, prior de Barrabés, prior de San Martin de Caballera, prior y sacristán de Monzón y precentor. Guillermo, que se identifica como prior de Barrabés $\left(n^{\circ}\right.$ 92) abadía sujeta a Roda ${ }^{39}$. Tan solo contamos con la necrológica de un obispo, Gaufredo ( $n^{\circ}$ 23I), cuya muerte es recogida también en el obituario de Pamplona.

Asimismo hallamos personajes de otras iglesias afines, y de localidades cercanas como Raimundo de Esdolomada ( ${ }^{\circ}$ I6I), o Juan de Rovinaco, rector de Esdolomada ( $n^{\circ} 249$ ), esto es, de la parroquial de San Saturnino en la población de Esdolomada al noroeste de Roda y que hoy conserva una iglesia magnífica levantada a finales del XIl y principios del XIII.

Como dije antes, entre los difuntos a rememorar existe un escogido grupo de laicos. La familiaritas debió suponer una inyección económica en un momento en que San Vicente de Roda había dejado de ser el corazón del obispado ${ }^{40}$. A esto debemos sumar la importancia que debía tener contar con el favor de una serie de personajes destacados de la sociedad que se convierten en sus aliados, los cuales al morir en campaña serían enterrados en el claustro. De ahí que no es desdeñable el índice de miles, esto es, protectores, que aparecen en el claustro. Como ejemplo mencionaré a Gombal que se asocia como miles primero y después ingresa en la

36. Las anotaciones en algunos casos son muy completas, con nombre, apellido y cargo eclesiástico: Bernardo de Avellana camerario ( $n^{\circ} 216$ ), Raimundo de Canosto, prior, fallecido en 1208 ( $\left.n^{\circ} 218\right)$, Guillermo de Meytat, canónigo y sacristán, fallecido en 1304 ( $n^{\circ} 114$ ); Bernardo de Gallifer, prior que murió en 1275 ( $n^{\circ}$ 82), Berengario de Girueta, prior fallecido en 1294; Juan de Statella, prior claustral ( $\left.n^{\circ} 178\right)$; Pedro de Turri, camerario, que murió en 1322 ( $\left.n^{\circ} 87\right)$; Arnaldo de Caferris, camerario fallecido en 1334 ( $n^{\circ}$ 221); Fortunio, que aunque no se identifica su apellido sí se identifica por su cargo, prior de Santa María de Nisnoi, muerto en 1241 ( $\left.n^{\circ} 246\right)$, Bertran Cornutella prior fallecido en $1309\left(n^{\circ} 261\right)$.

37. Berengario de Falc, $\left(n^{\circ} 151\right)$ Pedro de Roviñac, $\left(n^{\circ} 157\right)$.

38. GUDIOL, «Necrologi», nota 89

39. GUDIOL, «Necrologi» nota 8.

40. Cf. Grau Quiroga, Roda de Isábena en los siglos X al XIII. La documentación episcopal y del cabildo catedralicio, Institución Fernando el Católico, Zaragoza 2010. 
comunidad de ahí que su epitafio recoja ambas circunstancias «miles et canonicus». El padre Gudiol indica que la presencia tan cercana de los sarracenos hizo que fuera prudente la estrecha relación con la fuerza armada lo que se inaugure una fraternidad instituida por Guifret Bisbe de Roda y Barbastro, confraternidad instituida el domingo primero de junio de iı38. Esta sería la razón por la cual aparecen varios miembros de la milicia y que algunos se hicieran canonjes de Roda e identificados como canonicus et miles ${ }^{4 \mathrm{I}}$. Nos aparece un scutifer, Bartholomeus de Torailla, hombre de armas, ayudante de algún señor local, quizá de Guillermo de Aquilanit según Gudiol. No faltan los nombres de señores como Aspes o Espes o los Bisbe de Roda tan vinculados a la iglesia, algunos de ellos miembros destacados de la comunidad, en calidad de protector como Bertrán de Aspes, miles ( $n^{\circ}$ I23) o en calidad de miembro de la canónica como Pedro de Aspes precentor rotense $\left(\mathrm{n}^{\circ}\right.$ $\mathrm{I} 63)^{42}$. Gudiol identifica al obispo Gaufridus como un miembro de esta familia. En la Crónica de la ínclita y coronada ciudad de Valencia y su reino ${ }^{43}$ aparecen citados algunos de estos personajes como miembros destacados y elegidos por el infante Alfonso, hermano del rey don Pedro: Otrosi tenia el infante apercibidos cincuenta caballeros del principado alojados en la ciudad de Lerida los nombres de los quales son estos que se siguen (...) Cita a Gombal de Benavente, Bernardo de Aspes, Pedro de Meitad, Arnaldo de Corsaví, Berenguer de Puigvert, Arnaldo de Foxá, Remón Folc, Remón Roger. A estos hombres de armas debemos añadir otros personajes masculinos y mujeres que aparecen en el necrologio por derecho propio, sin duda, por ser beneficiarios de la iglesia ${ }^{44}$. Entre las féminas se recogen la defunción de Richilda (nonas de marzo), y Sebilia de Logra (VIIl idus de marzo de I280), Elisenda De Aspes en el año i28ı. Una mujer, Beatriz de Casteylo, hija de Ferri de Casteilo, que falleció en I3I7 fue enterrada posiblemente en el claustro de la catedral.

\section{EL TALLER DE RODA. ACTIVIDAD Y PRINCIPALES LAPICIDAS}

El taller lapidario estaba estrechamente vinculado al scriptorium donde los canónigos, y clérigos expertos elaboraban biblias, libros litúrgicos, el necrologio originario y hoy desaparecido, además de confeccionar negocios jurídicos para sí y para las gentes que solicitaban sus servicios. Toda esta actividad escrituraria y su calidad quedan perfectamente reflejadas en nuestros epígrafes. El scriptorium

41. GUDIOL, «Necrologi», nota 33 .

42. Son varios los miembros de esta familia que aparecen recogidos en el necrologio: II kalendas marcii obiit Bertrandus Daspes miles, VI kalendas octobris obiit Arnallus Daspes, IIII Kalendas Augusti obiit Bernardus et Raimundus Daspes, III kalendas februarii obiit Bort de Aspes milesd

43. MARTí DE VICIANA, Libro tercero de la crónica de la ínclita y coronada ciudad de Valencia y de su reino, a cargo de Joan Iborra, Valencia 2002.

44. Raimundo del Marcadal ( $\left.n^{\circ} 233\right)$, Frotinio de Beranvi ( $\left.n^{\circ} 248\right)$, Bernardo Tager fallecido en $1223\left(n^{\circ} 260\right)$. 
mantiene una actividad continua tanto en producción documental, como libraria y epigráfica. Estos tres elementos u objetos escritos tienen una finalidad diferente pero su constitución participa de un mismo grupo humano y como no podía ser de otro modo las transferencias de unas a las otras son inevitables.

Antes del siglo XIII no tenemos vestigios de un taller lapicida rotense. La necesidad de publicitar de manera permanente un mensaje fuera de carácter intelectual o didáctico, fuera de índole jurídica, no existía. De hecho, aparte del obituario, una sola inscripción ha llegado al día de hoy, la referente a los siete obispos rotenses situada en el interior del templo, lo que nos indica el uso tan concreto que se hace de la epigrafía y del carácter eminentemente conmemorativo y litúrgico de ésta. Pero el conocimiento y la técnica epigráfica se manifiesta en el siglo XIII como un proceso ya maduro, contando con lapicidas que conocen bien su oficio y que sientan las bases y peculiaridades del taller. Sabemos que a pesar de la unidad gráfica cada centro productor aporta su matiz propio a los objetos escritos lo que nos permite diferenciar sus obras del conjunto general. En Roda las particularidades gráficas se configuran ya en las primeras anotaciones necrológicas trasladadas a piedra.

\section{IV.1. ETAPA INICIAL 1200-123045}

De este periodo inicial conocemos unas pocas inscripciones, todas ellas localizadas en la panda sur, y que tienen en común además de la escritura, el tipo de soporte -el ábaco-y el formulario. Se trata de una escritura que tiende a los trazos rectilíneos, de surco sencillo, con alguna concesión en la forma de la $\mathrm{O}$, pero en su conjunto mantiene la pureza de trazos. Hallamos algunas características que se desarrollarán posteriormente como el signo Z para la S o la decoración perlada de alguna letra aislada (fig.I). Los textos corresponden a los siguientes meses: $V$ nonas madii obiit Garsias canonicus et sacerdos; XII kalendas septembris obiit Raimundus canonicus et sacerdos; la fragmentada [..] canonicus ]...] XVIII kalendas[...]; XVII kalendas ianuarii obiit Petrus canonicus et sacerdos; VII idus augusti obiit Guillelmus canonicus et sacerdos; X kalendas febroarii obiit Bernardus canonicus et sacerdos; VII idus augusti obiit Berengarius. Todos ellos figuran en el obituario de Pamplona: Garsia el 3 de mayo, Raimundo el 2I de agosto, Pedro el I5 de diciembre, Guillermo el 7 de agosto, Berengario el 7 de agosto, Bernardo el 23 de enero, aunque solo el primero, Garsia, se identifica como rotense específicamente. Este

45. Ciertamente la actividad epigráfica se inicia en el primer tercio de siglo, sin que podamos precisar más sobre una fecha. De admitir el año 1225 como el inicio de la actividad, propuesto por Durán Gudiol, esta etapa inicial sería breve. El año 1230 está determinado por el final de la actividad de los lapicidas del periodo y el comienzo de la actividad del maestro de Roda. 
hecho confirmaría la ejecución de estas piezas antes de I232, fecha del envío del necrologio a Pamplona.

Su escritura es una gótica aún poco evolucionada donde predominan ciertas características gráficas de la carolina ${ }^{46}$. No olvidemos que la escritura gótica no es un alfabeto nuevo sino la evolución morfológica del alfabeto carolino con tendencia a redondear o exagerar las formas de las letras unciales, a duplicar trazos y líneas ornamentales ${ }^{47}$. La primera evidencia de la evolución de la escritura a formas góticas se aprecia en la producción libraria ${ }^{48}$, donde las formas redondas y el cerramiento de las letras aparecen tempranamente en los rotuli a

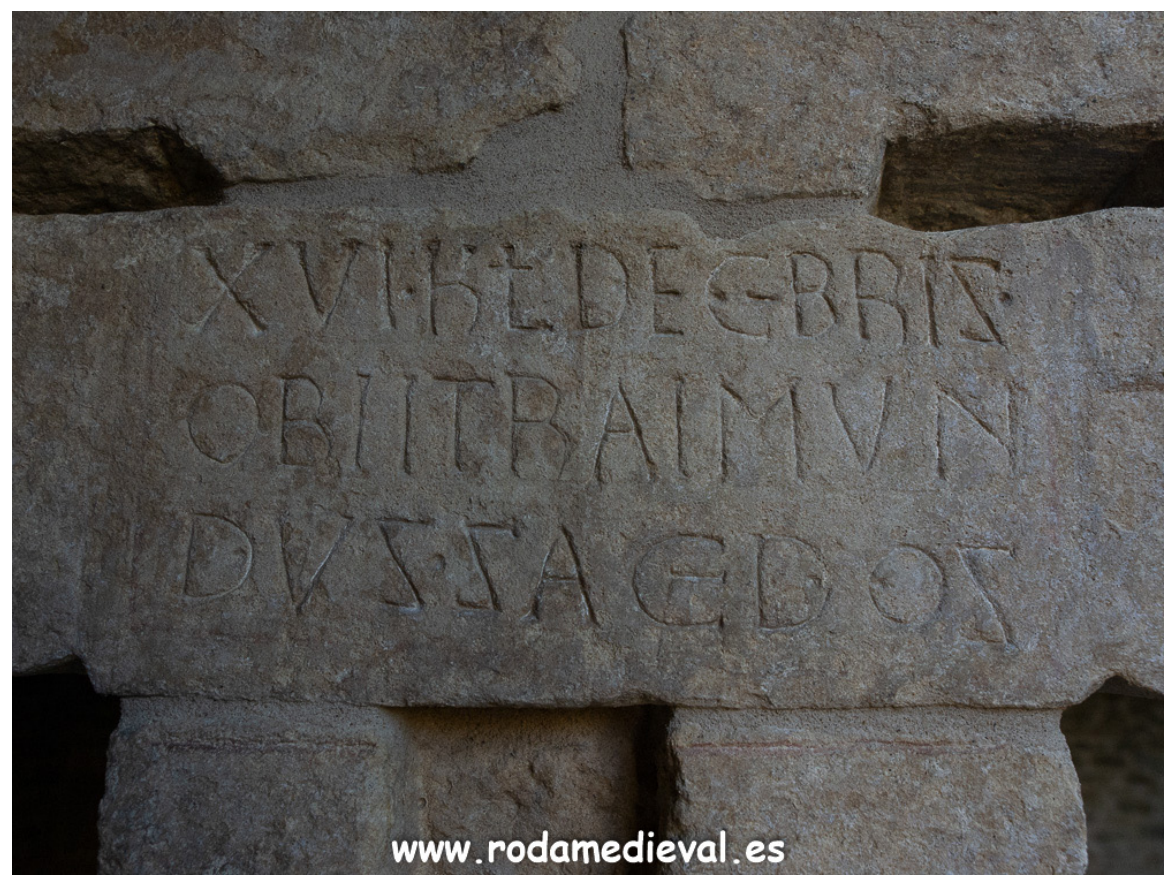

FIGURA 1. PANDA SUR MANO A

46. En el proceso de la carolina a la gótica, la escritura ha recibido diferentes nombres, carolina avanzada, pregótica. Marín Martínez, Tomás, Los códices de Santo Martino. Singularidades paleográficas, Santo Martino de León. Ponencias del I Congreso Internacional sobre Santo Martino en el VIII centenario de su obra literaria 1185-1985, León, 1987, p. 445; RuIz Asencio, José Manuel, Colección documental del archivo de la catedral de León, VIII (1230-1269), León, 1993, XXIX; GutıÉrrez Álvarez, Maximino, Corpus Inscriptionum Hispaniae Mediaevalium, Zamora, 1.2, Brepols, Turnhout-León, 1995, p. 77.

47. Esta definición del alfabeto mayúsculo gótico es de Batelli, que hace suya en su estudio sobre las grafías góticas, Francisco J. Molina. Cf. BATELLI, lulio, Lezioni di paleografía, 227; Corpus Inscriptionum Hispaniae Mediaevalium. vol. 3 Valladolid, p. 55. Sobre el origen y evolución de la escritura gótica en el ámbito europeo contamos con el estudio de síntesis de $\mathrm{KoCH}$, Walter, «The gothic script in inscriptions. Origin, characteristics and evolution», en Las inscripciones góticas, /l Coloquio Internacional de Epigrafía Medieval, León 2010, pp. 9-29.

48. Cf. MARTín López, Ma Encarnación, «La escritura gótica epigráfica», en Paleografía I/ Las escrituras góticas desde 1250 hasta la imprenta. V Jornadas de la Sociedad Española de Ciencias y Técnicas Historiográficas, Oviedo 2007. 


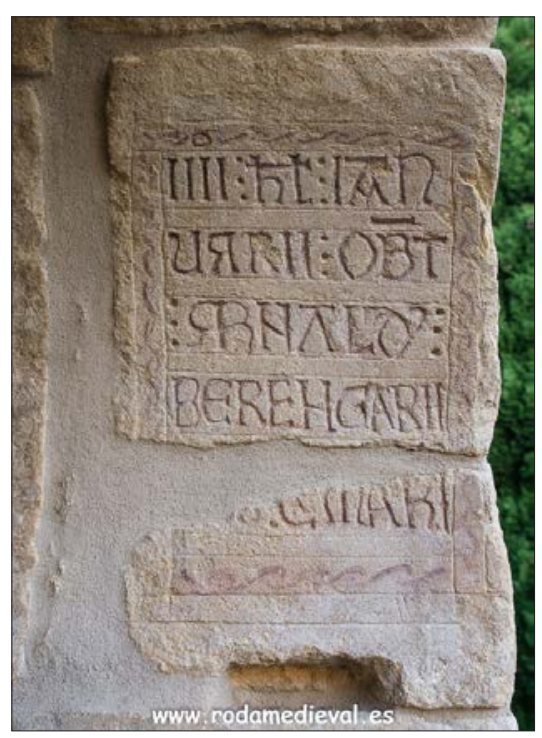

FIGURA 2. MANO B

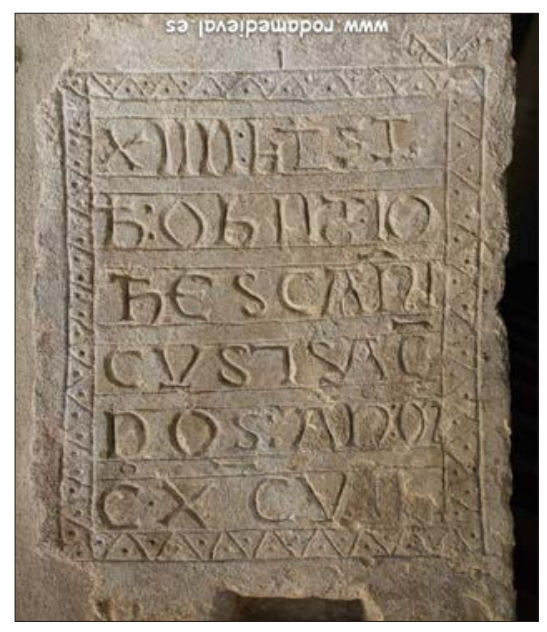

FIGURA 3. MANO C finales del siglo XII. A diferencia de otros países, como Italia donde las variantes son evidentes entre las distintas regiones ${ }^{49}$, la gótica en España es uniforme en su morfología en todo el territorio, aunque con algunas particularidades. Esto nos permite hacer un análisis comparativo respecto a otros centros productores a fin de determinar la cronología de cada letrero.

Todas ellas presentan una misma impaginatio, con marcada tendencia a la horizontalidad, y una armónica disposición del texto sin necesidad de nexos o cruzamientos. La delimitación de la superficie o campo de escritura se realiza mediante las líneas marginales dobles que posteriormente serán incisas y que «enmarcarán» el texto. Las líneas rectrices son dobles y son marcadas suavemente sobre la superficie con intención de no destacar sobre el texto ${ }^{50}$. El resultado final es ordenado, simétrico. Por otra parte, la disposición del texto será continuada por el conjunto epigráfico: día y mes, verbo notificativo obiit, nombre del difunto, cargos. La separación de palabras se realiza mediante uno o dos puntos, sin seguir un criterio único. Predominan los nombres de pila sin apellidos o topónimos que ayuden a su identificación, y no falta el cargo «canonicus et sacerdos», menos en el caso de Berengarius.

Tras las primeras ejecuciones, de marcado carácter clásico, el taller tiende a las formas unciales, mostrando las pautas del necrologio pétreo: verticalidad de la caja de escritura, enmarcado de la inscripción, diversidad gráfica en una misma letra ${ }^{5 \mathrm{I}}$ Es el caso de la mano B (fig. 2). Se combina la E uncial y la rectilínea, el trazo intermedio de la $\mathrm{N}$ es casi horizontal, la A simétrica se combina con la A de trazo izquierdo curvo y estrangulado. Pertenece también a este periodo, la mano $\mathrm{C}$, con un enmarcado que es decorado simplemente en zigzag. Se introduce la T uncial quebrada en su cuerpo central, la A de cuatro trazos con travesaño angular, el signo tironiano «et» de

49. De RubeIS, Flavia, «La capitale romanica e la gótica epigrafia: una relazione difficile», en Las inscripciones góticas, II Coloquio Internacional de Epigrafía Medieval, León 2010, p.19o.

50. Es lo que denominamos impaginatio técnica, frente a la estética que se desarrollará a partir de 1250. Sobre los diferentes tipos de impaginación tomamos como referencia el análisis de GARCíA MORILLA, Alejandro «La impaginatio en las inscripciones del románico burgales», en Impaginatio en las inscripciones medievales, León 2011, pp. 215-229.

51. DURÁN GUDIOL, «Las inscripciones medievales», num. 258. 
trazo angular, caracteres todos ellos que se mantendrán y fijarán en la siguiente década (fig. 3).

\section{IV.2. SEGUNDO PERIODO, EL TALLER DEL LLAMADO MAESTRO DE RODA 1232-1242}

Esta nueva etapa está marcada por la actividad de un lapicida de gran destreza con el cincel y el martillo que le confiere el apelativo de «maestro» por Durán Gudiol. Su actividad debemos hacerla coincidir con el final de la etapa anterior, entre I230-I232, una cronología basada en la confección del libro obituario y su envío a Pamplona, y deja de trabajar hacia I242. La última inscripción que podemos atribuir a su mano en efecto corresponde a este año y es señalada por Gudiol como la número ig6.

El maestro lapicida logra un alfabeto dinámico que creará escuela y será la seña de identidad de la catedral de Roda-mano MR-, con una calidad gráfica muy superior al resto de los centros oscenses. La particularidad de este lapicida no es la creación de formas, ya que se inspira en modelos ya existentes procedentes de códices y de otros talleres lapicidas. Su originalidad está en la combinación de elementos gráficos y su articulación en el texto, así como la destreza de ejecución que confiere a sus piezas de una singularidad de difícil imitación. No es extraño que tenga seguidores e imitadores, o simplemente, discípulos. El alto número atribuidas a su autoría nos preguntamos ¿todas las creaciones son atribuibles al maestro, o por el contrario hallamos la mano y contribución de otros lapicidas del taller? Es necesario hacer primeramente un repaso por el volumen de inscripciones atribuidas al maestro de Roda. Del conjunto lapidario atribuido por Gudiol a MR, I22 inscripciones, tras un análisis paleográfico diecisiete de ellas no podemos atribuirlas a su mano, pero podría pertenecer a oficiales de su taller o que aprendieron con él y posteriormente siguieron las tareas lapidarias ${ }^{52}$. Para dejar claro el criterio a seguir para el descarte de las piezas analizaré lo que considero la escritura epigráfica del MR en un apartado dedicado a su obra.

Las formas rectilíneas de la etapa anterior son sustituidas por las formas redondas predominantes en todo el conjunto. Una de las características de MR es la brotación o el engrosamiento de las partes medias de los trazos curvos, elementos comunes en el ámbito del libro manuscrito, y del epigráfico. Es un estilo gráfico que se extiende por Europa, así lo encontramos en formas elaboradas en ejemplos epigráficos cronológicamente próximos a los rotenses en Francia e Italia ${ }^{53}$. En

52. Se trata de las siguientes inscripciones, con numero de apéndice de Durán Gudiol, 86, 88, 91,109, 113, 139, 140, $164,186,206,213,216,218,224,229,234,261$

53. Estas características las hallamos en inscripciones del pavimento de San Miniato al Monte, del baptisterio de San Giovanni, en territorio florentino, pero también en otros territorios como Lucca y Pistoia aparecen estas grafías. 
efecto, la evolución de la escritura gótica lleva consigo un momento de vuelta o de respuesta a la progresiva estandarización de la morfología de las letras y de su estética. De ahí que letras como la A abandonen su forma tradicional y presenten tipos novedosos y originales. Será frecuente un trazo de coronamiento horizontal, que será característico en esta letra a partir de I230.

\section{IV.3. TERCER PERIODO DEL TALLER. 1242-1299}

La última intervención de MR se realizaría en torno a I242. Esta fecha nos determina el inicio del tercer periodo del taller. Se mantiene las particularidades gráficas de la etapa anterior, pero perdiendo la destreza y la elegancia de las formas de la generación anterior. Se imponen formas más marcadas donde la incisión destaca ciertos trazos de las letras marcando los claroscuros, propio de la evolución de la escritura. La escritura gótica continúa su evolución hacia formas cerradas como la E, S L, que remata el trazo horizontal con un pequeño trazo que irá adquiriendo cada vez más protagonismo. En la panda sur se siguen incorporando

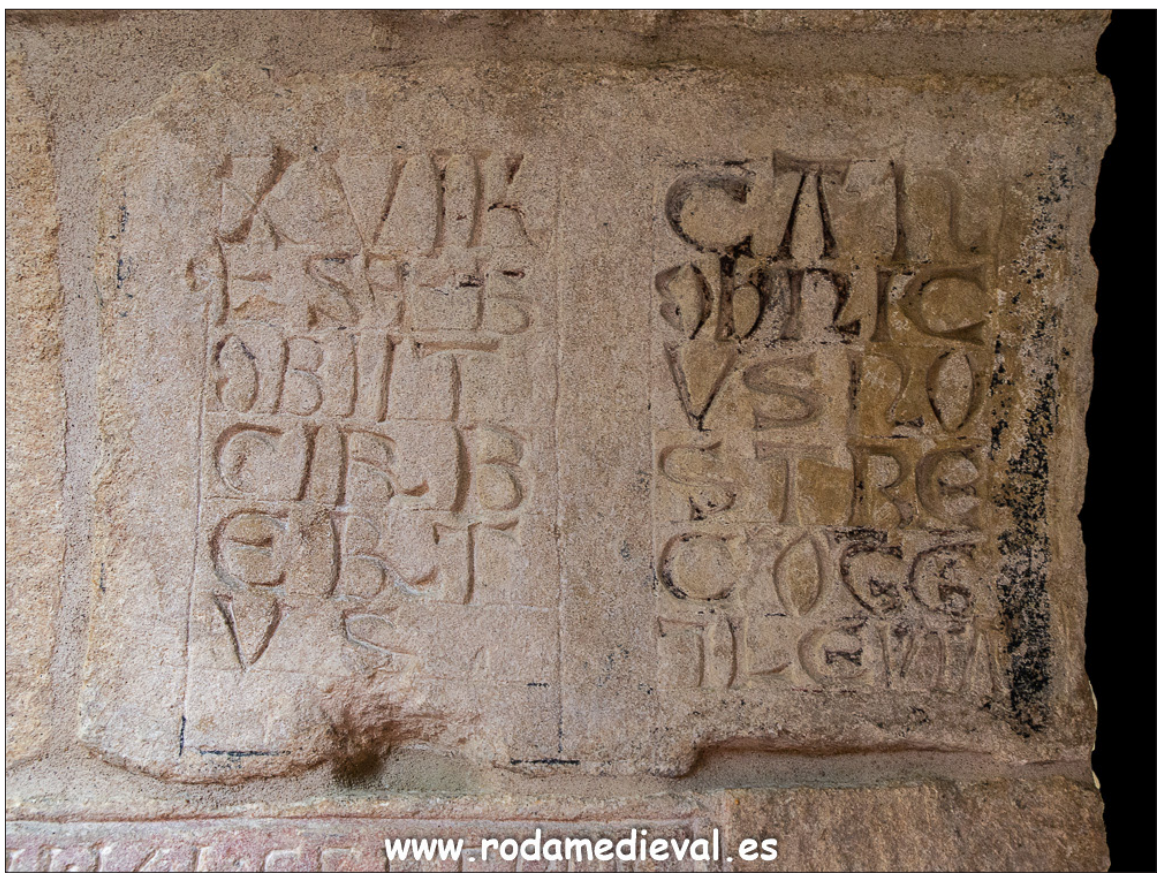

FIGURA 4. N 198 MANO D

Véase sobre la producción epigráfica del siglo XIII el estudio de GRAMIGNI, Tomasso, Iscrizioni medievali nel territorio fiorentino fino al XIII secolo, Firenze press, 2012, concretamente pp. 78-88. 
nuevos letreros - mano D- muy dispares en su calidad. Se intenta mantener una impaginación doble como las piezas ejecutadas por MR en la sala capitular, pero sin alcanzar su destreza (fig. 4).

Ahora trabaja un fiel seguidor del MR, de escritura elegante y epígrafes armoniosos que denominamos mano E. Su estilo podemos verlo en el óbito de Benedicto, canónigo de Roda que falleció en I25I (fig.5). El letrero muestra todos los indicios de una gótica de módulo ancho que tiende a acortar el astil de las letras como la D uncial y a agrandar los trazos curvos de las letras. Se aprovecha este desmedido agrandamiento del cuerpo de las letras para insertar otras dentro como se aprecia en la línea 5. Exagera así mismo el estrangulamiento de letras como la $\mathrm{N}$ uncial. En general las letras tienden al cerramiento, que se observa completo en la $\mathrm{E}$ uncial, pero que se manifiesta en la D, la G. La A presenta varias grafías, la simétrica, la A curva y aparece ya la A de cuatro trazos, el primero curvo con un

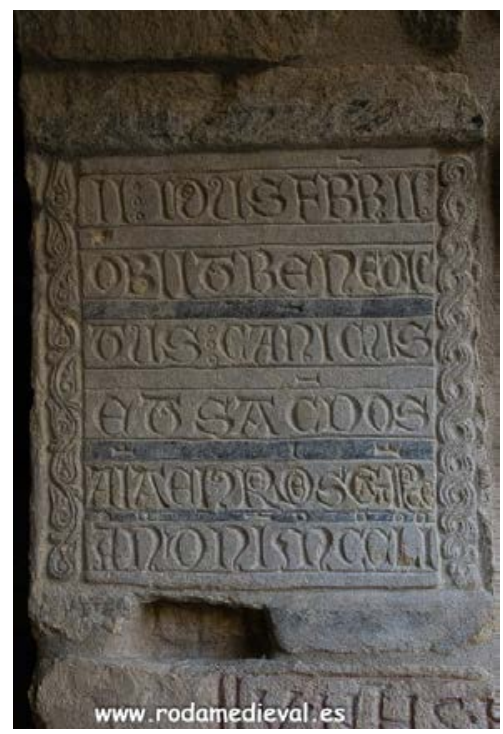

FIGURA 5. N $N^{\circ} 113$. PANDA SUR MANO E coronamiento asimétrico que se alarga a la izquierda. La M en forma de omega estrangula su cuerpo lo mismo que la $\mathrm{D}$, la $\mathrm{O}$. Todos los remates de las letras se incurvan hacia dentro. El signo o semicolon de -us, adquiere ya el valor de mayúscula inscribiéndose en las paralelas de escritura. En definitiva, se trata de una ejecución producto de una de las últimas campañas de actualización del obituario realizado en las últimas décadas del siglo XIIl.

\section{IV.4. CUARTO PERIODO. EL TALLER EN EL SIGLO XIV}

Las tareas de transliteración del Necrologium experimentan un descenso de producción. Las campañas de actualización se distancian. Al menos ocho son los lapicidas que realizan las 13 inscripciones de este periodo. La figura 6, en la panda sur, -mano F- es una ejecución relativamente temprana de la actividad en este siglo. La escritura gótica experimenta una tendencia al prolongamiento del módulo de las letras apreciable ya en la G, A, N. Los trazos de las letras tienden a remarcarse con un trazado profundo que llega a la exageración en el caso de la $\mathrm{T}$ uncial con un coronamiento exagerado y desmedido. La A asimétrica muestra un

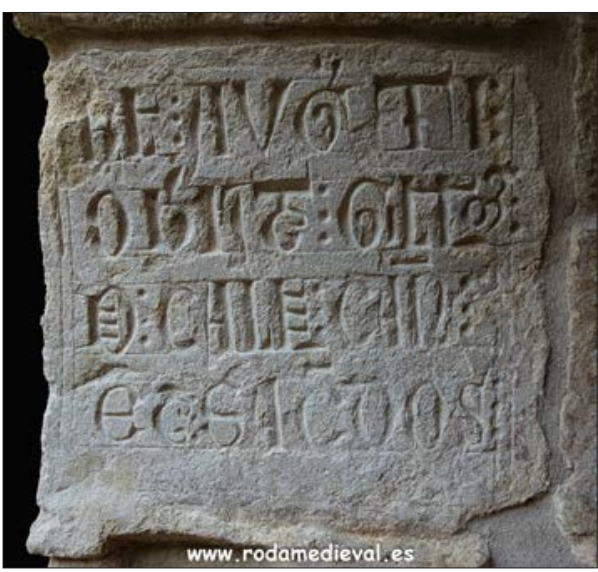

FIGURA 6. N ${ }^{\circ} 191$ PANDA SUR MANO F 


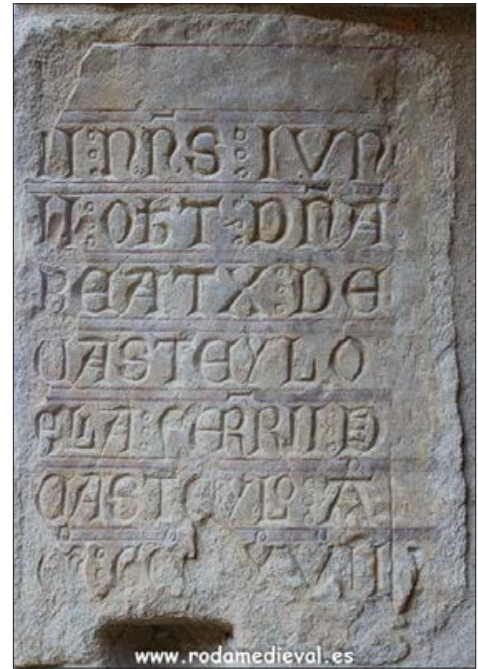

FIGURA 7. $\mathrm{N}^{\circ} 173$ MANO G

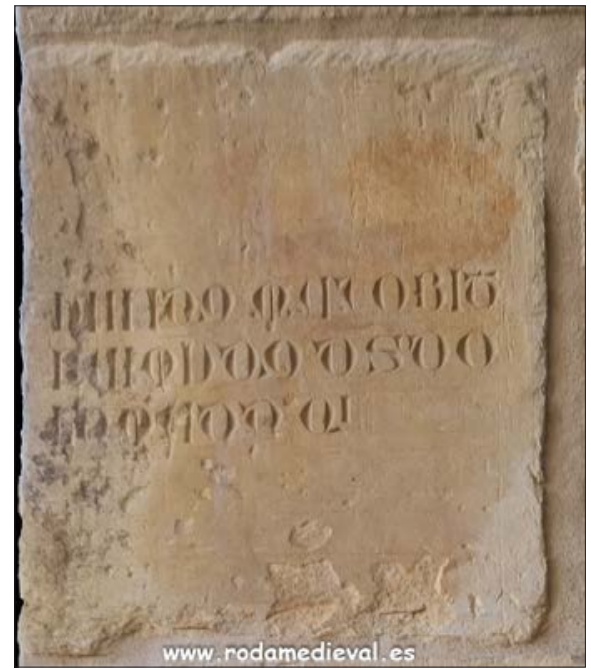

FIGURA 8. PANDA OESTE MANO G2

engrosamiento de los trazos. La D desarrolla el arranque superior e inferior a los extremos superando el trazo vertical. La E uncial así como la S tienden a cerrar. Este mismo lapicida realiza la anotación de Petrus socius ( $n^{\circ}$ I93 de Durán Gudiol) aunque no presenta los trazos tan marcados. Es fácilmente identificable por la ejecución de la $\mathrm{G}$ que forma un cuerpo en espiral, estrecho abajo.

Un segundo lapicida -mano G- realiza otras dos inscripciones en la panda sur y norte ( $\mathrm{n}^{\mathrm{O}}$ II3, I73 Durán Gudiol) se redondean los trazos, las letras se cierran completamente como la E, la S, la T uncial. El módulo es cuadrado. Se añade el color en el fondo (fig. 7). Cercana a esta mano - mano G2- trabaja un lapicida del que solo conservamos una pieza, caracterizado por su módulo cuadrado y letras de trazos anchos y redondos (fig. 8).

En la panda Este hallamos ejecuciones de un lapicida con carácter propio -mano $\mathrm{H}$ - que realiza unas pocas piezas, como el óbito de lohannes de Statella, prior claustral, que como la anterior debemos situarla cronológicamente en la primera mitad del siglo XIV 54 . Aunque Gudiol la data entre I250-I299, el doble trazado a punzón del diseño de algunas letras como la I, y su cincelado posterior, ofrecen un resultado estético de fuertes contrastes de claroscuros, que serán característicos de la escritura gótica a partir de I300 (fig. 9). Se observa en este lapicida no tanto el cerramiento de las letras cuanto la angulosidad que adquiere la $\mathrm{O}$ recordando la antigua vocal visigótica. Predomina la A asimétrica y el surco se engrosa en el cuerpo central de las letras como la I. La L sigue su ascenso del remate bajo. Por

54. Debemos posponer la fecha de ejecución de esta pieza, datada por Gudiol en la segunda mitad del XIII, y que cataloga en su colección epigráfica con el núm. 177. Cf. DuRÁN GUDIOL, «Las inscripciones medievales», p. 87. 


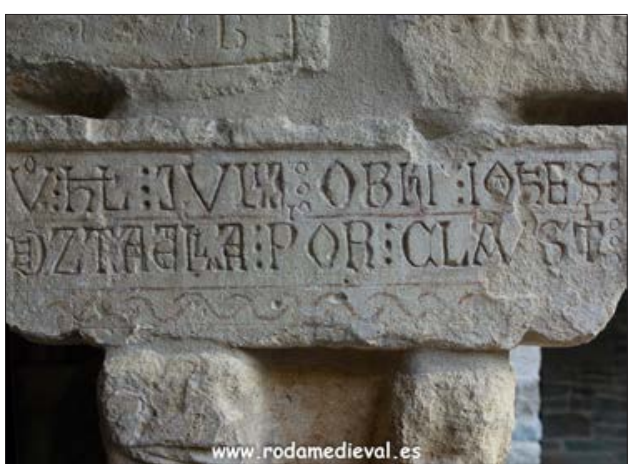

FIGURA 9. $\mathrm{N}^{\circ}$ 177, PANDA ESTE MANO H

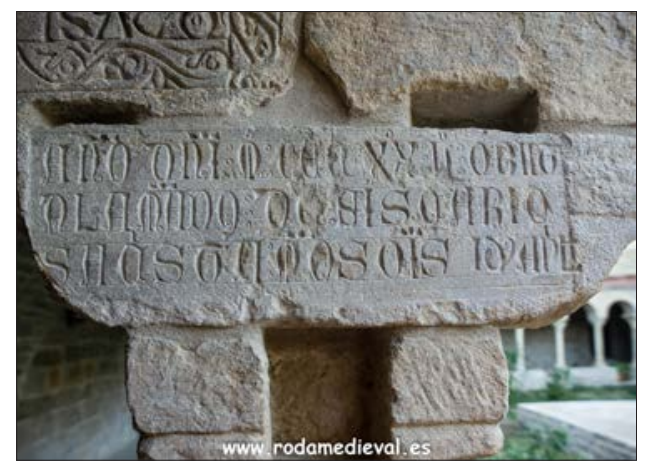

FIGURA $10 N^{\circ} 143$, PANDA SUR MANO

su parte la separación de palabras opta por combinar los tres puntos incisos con los círculos esgrafiados. Entre los primeros trabajos de este lapicida hallamos en la misma panda este el óbito de Bernardo de Galliler, prior, ( $\mathrm{n}^{\circ} 89$ Duran Gudiol) donde muestra ya su toque personal con la geometrización de los cuerpos redondos de las letras, en este caso la D uncial.

A mediados de siglo, el módulo de las letras experimenta un alargamiento (fig. Io $)^{55}$ los signos de separación son tres círculos simétricos marcados simplemente a punzón, como a punzón es marcado el travesaño doble de la A. En el taller trabajan otros lapicidas. Podemos apreciarlo en el óbito de Petrus de Aspes (Daspes) precentor rotense, fallecido en $\mathrm{I300.} \mathrm{Gudiol} \mathrm{atribuye} \mathrm{al} \mathrm{siglo} \mathrm{XIII} \mathrm{la} \mathrm{ejecución} \mathrm{del} \mathrm{óbito} \mathrm{de} \mathrm{Petrus}$ de Pedrulo, en la panda oeste. Sin embargo, las grafías y características de algunos elementos como el signo de -us ya muy bajo formando parte de las mayúsculas, es indicativo de una ejecución por el taller en el siglo XIV.

En este periodo hallamos circunstancias aisladas de una doble anotación en una misma pieza ${ }^{56}$. Es el caso de los óbitos de Petrus y Raimundus, ambos socios de la canónica, que ocupan respectivamente las líneas I-3, y 4-7. La doble anotación estaba ya prevista como así lo muestra el proceso de conscriptio de la inscripción. En cuanto a su autor material, Gudiol atribuye esta pieza a la mano del MR llevado, sin duda, por la calidad del epígrafe. No obstante, por las grafías tan acusadas al cerramiento, la geometrización de la $\mathrm{O}$, debemos considerar su ejecución como obra del taller del siglo XIV y realizadas por el lapicida de las inscripciones anteriores.

Como va a suceder en otros centros monásticos, el obituario en piedra, y asociado a él, el taller lapicida, entran en franca decadencia en la segunda mitad del siglo XIV para desaparecer toda actividad epigráfica de la misma forma que surgió, de repente.

55. Por una errónea lectura, debido a su estado de conservación, Durán Gudiol consideró como última inscripción datada el epitafio de Escario (1413, abril, 13) n 143, situado en el muro de la panda sur. Gracias a las últimas restauraciones sabemos que esto no es así. Hoy las tareas de limpieza llevadas a cabo nos permiten contemplar el texto y completar su lectura, así como precisar su fecha: ANNO D(omi)NI: M: CCC: XX: II: OBIIT/ALAMANDO DE SISCARIO/SACRISTA: $M O(n) S O(n) I S: I D($ us) AP(r)IL (is). Esto es, 13 de abril de 1322.

56. Cf. DURÁN GUdIOL, «Las inscripciones», núm. 85 y 193, pp. 110, 135. 


\section{LA ESCRITURA DEL MAESTRO DE RODA PECULIARIDADES}

El estilo gráfico de esta inscripción de la fig. in sería un ejemplo típico de su producción y que destaca por su diversidad y estética. Como en otras piezas coetáneas la caja de escritura se dispone en el intradós del arco, y aprovecha la verticalidad del sillar para crear esta página pétrea. El texto se dispone en cinco líneas cada una porta una o dos palabras. La disposición textual siempre es idéntica; primera línea data, día del mes, segunda línea mes, tercera línea verbo notificativo y nombre, cuarta y quinta cargos. Las letras están aisladas, sin nexos, con una inserción de la I en A, para Raimundi, pero las palabras carecen de separación. El signo de puntuación solo se emplea en la primera línea, en la data, y consiste en el propio de MR y su escuela, esto es, un punto central y

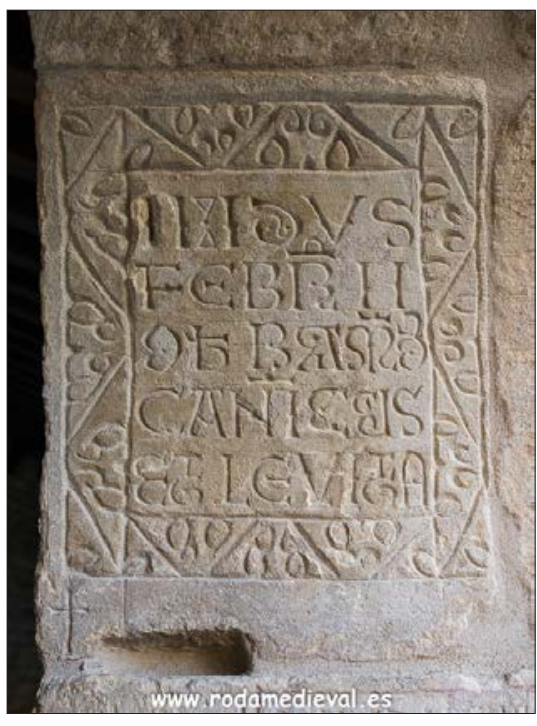

FIGURA 11. N $N^{\circ} 112$ PANDA SUR, MAESTRO RODA dos formas triangulares de surco tenue. La escritura es una gótica que combina las formas capitales y unciales y añade grafías nuevas a base de estrangulamientos. Combina formas para no repetir, creando así un conjunto dinámico a la vez que armónico.

En este caso, tres veces aparece la A y las tres son tipos diferentes, la A capital, la A de un trazo curvo, la A con trazo primero mixto, con sección recta y sección curva, dando a la letra una forma de R invertida muy particular. Esta A es una clara inspiración en las letras capitales de los rotuli librarios. Lo mismo sucede con la E tres veces aparece y emplea dos formas: la uncial con su característico travesaño separado y claramente marcado sus extremos por el punzón, y la E épsilon. La U es minúscula con módulo agrandado, y presenta una grafía curiosa, quebrando el trazo curvo izquierdo en dos segmentos. La T uncial quiebra así mismo el cuerpo estrangulado en su parte superior. La O presenta su forma de riñón, que no es otra que el estrangulamiento del trazo curvo izquierdo. Lo mismo sucede con la $\mathrm{D}$ uncial. La C presenta dos tipos en las dos ocasiones que aparece; una grafía redonda, y una versión donde estrangula el cuerpo de la letra. La R presenta dos variantes, una remata su tercer trazo hacia dentro, otra incurva el trazo hacia arriba. Entre las particularidades de MR tenemos la forma de abreviar obiit, OB, con la b minúscula atravesada por el signo de abreviación que se convertirá en una constante en estas piezas. Se observa en la ejecución de MR su formación en el scriptorium y su conocimiento de la decoración y escrituración de libros, de 
manera que en su obra epigráfica hallamos claros paralelismos con los códices, así es la decoración interna que recibe la letra $\mathrm{D}$, o la diversidad de formatos de la A de inspiración libraria. No falta la decoración perlada o de borlas en los puntos centrales de las letras y numerales, que así mismo se emplean en los documentos del scriptorium rotense. Todo ello nos habla de una mente imaginativa que busca ante todo la estética del letrero, una estética que por sí misma llame la atención del lector lo que inspiró a Gudiol para calificarle de «maestro».

\section{V.1. OTROS LAPICIDAS CON MR}

Otras inscripciones presentan las mismas pautas de ejecución y estéticas establecidas, que son ejecutadas por la misma mano y que trabajan al tiempo que MR o a sus órdenes. Esto explicaría la abundante obra atribuida al MR ya que los caracteres externos son muy similares, de ahí que Gudiol atribuyera I22 inscripciones a una sola mano. Brevemente haré alguna indicación sobre algún lapicida de su «escuela», pues el espacio no permite tratar todos ellos. En la panda oeste se inscribe el óbito del converso Bonetus, ejecutada por un lapicida muy próximo a $\mathrm{MR}$, que se identifica por algunas peculiaridades como la confección de la $\mathrm{S}$ de curvas asimétricas, y la diferencia de $\mathrm{V}$ con valor consonántico mediante un trazo horizontal en la base de la

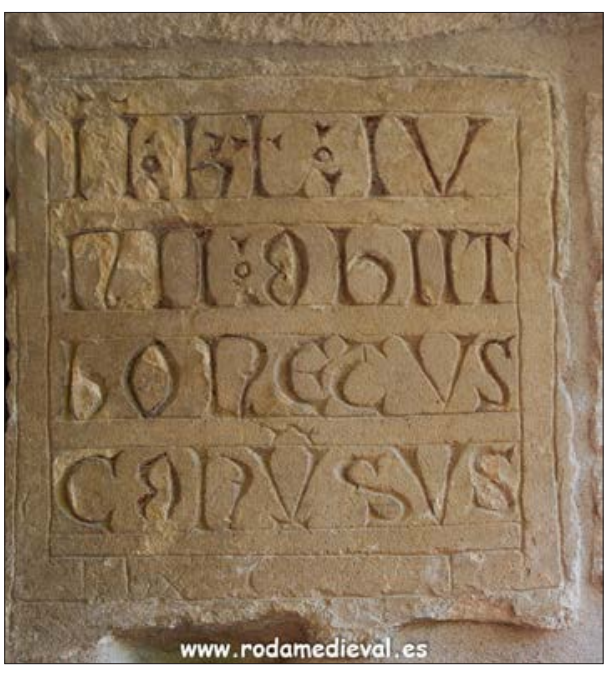

FIGURA 12. COETÁNEO A MAESTRO DE RODA letra (fig. I2) Las letras presentan un surco con una incisión irregular, profunda en la parte superior de las letras, fino en la inferior, dando sensación de pesadez al conjunto. La $\mathrm{C}$ redonda y la $\mathrm{E}$ uncial rematan en pequeños trazos, como la $\mathrm{L}$ que dan carácter a las letras y tienden a cerrarlas. El cuerpo de la $\mathrm{N}$ minúscula o uncial, la $\mathrm{O}$ y la $\mathrm{T}$ uncial se estrangulan, siendo características de la estética rotense. Los signos de puntuación son idénticos a los que empleará MR pero la ejecución del conjunto es más tosca. Tosquedad que se aprecia en la ejecución de la b minúscula y la $S$. El cuerpo de la b no se cierra y la doble curva de la $S$ es irregular, particularidades éstas que lo identifican.

No podemos dejar de admirar la correlación entre su obra lapidaria y el taller librario. Sin duda, el maestro de Roda era un miembro más del scriptorium rotense. Conocía bien los libros que se escribían allí e incluso, por qué no, fuera uno más en su ejecución. No sería el primer maestro que trabaja en distintas materias escriptorias. En San Miguel de Escalada contamos con un grupo de amanuenses 
que trabaja tanto en pergamino como en piedra. Sirva de ejemplo el caso de Elías, canónigo de San Rufo que escribe y suscribe como notario del monasterio algunos documentos privados de éste y también y, a la vez, aparece suscribiendo como amanuense en un folio de un códice, y no tiene problema en la ejecución epigráfica, firmando «Elias fecit» en una inscripción del pórtico ${ }^{57}$. Sea como fuere, lo cierto es que, sirviéndose de su habilidad gráfica, nuestros anónimos maestros lapicidas elaboran una imagen gráfica propia y característica de Roda que la distingue de otros talleres. El relieve que la comunidad pretende dar a los mensajes funerarios de estas piezas obliga a crear unos epígrafes fuera de lo corriente, elegantes, elaborados con alfabetos creativos e inventados, explotando al máximo los recursos gráficos y creando un carácter subjetivo a estas piezas que las hace únicas.

\section{V.2. RELACIONES CON OTROS CENTROS PRODUCTORES}

Algunas formas gráficas son generales y comunes tanto en epigrafía como en libros y documentos como vemos en las imágenes fig. Iза Iзb. El documento corresponde al fondo propio de Roda. Se trata de una copia simple de un documento pontificio. En la primera línea, realizada en mayúsculas para darle más solemnidad, vemos letras decoradas con borlas ${ }^{5}$. Estas mismas soluciones estéticas están en las inscripciones de MR donde parece indiscutible la comunicación entre los diferentes soportes.

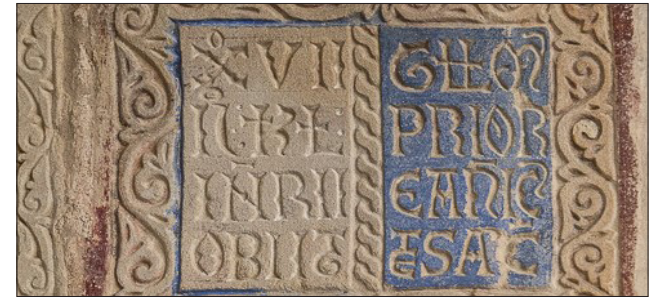

FIGURA 13A. FRAGMENTO INSCRIPCIÓN MR

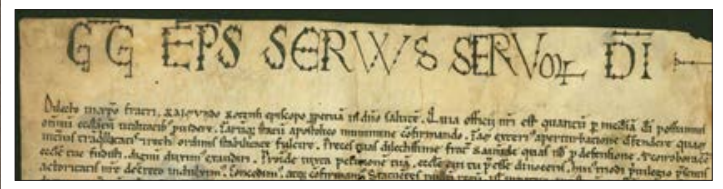

FIGURA 13B. FRAGMENTO DOCUMENTO ARCHIVO RODA

Pero también hallamos paralelismos más allá de los Pirineos. Se ha dicho anteriormente cómo la escritura gótica presenta las mismas características en el territorio peninsular. Pues bien, hallamos igualmente paralelismos en centros franceses donde la solución gráfica de algunas letras peculiares que tenemos en

57. Cf. García Lobo, Vicente, Las inscripciones de San Miguel de Escalada, Barcelona 1982; ID, San Miguel de Escalada, eds. García Lobo, V. y Cavero, G., León, 2013.

58. La decoración de borlas tiene un largo recorrido como elemento ornamental. Lo hallamos en un documento de 1122 del obispo de León, conservado en el archivo catedralicio. Anteriormente la cancillería de Alfonso VI lo emplea para la decoración de sus documentos, especialmente, en los crismones. Pero será en el ámbito librario donde hallemos más ejemplos. Desde los códices visigóticos, pasando por los carolinos hasta llegar a los góticos esta decoración reaparece con frecuencia. Ejemplo de ello sería la biblia ms. 962 fol. 36r del Morgan Library. 
Roda aparece en tierras galas. En efecto, en la abadía benedictina de Saint André le Bas, en la ciudad de Vienne en Dauphiné, hallamos algunas inscripciones que presentan estas mismas características. El primer caso es el epitafio del subdiácono Humberto, cuyas grafías góticas son similares a las que hallamos en Roda ${ }^{59}$, como lo son las ejecutadas en el epitafio de Geofrei Baudoin ${ }^{60}$, o en el epitafio de Ermengarda, donde hallamos dos elementos de MR, esto es, la puntuación en forma de triángulo y la $\mathrm{E}$ uncial de travesaño independiente ${ }^{6 \mathrm{I}}$, así como igualmente la $\mathrm{Z}$ en valor $\mathrm{S}$.

\section{FUNCIONALIDAD DE LAS INSCRIPCIONES. TRANSFERENCIAS DEL LIBRO A LAS INSCRIPCIONES}

Podría parecer que el concepto de diseño gráfico sería extravagante llevarlo a la Edad Media, pero nada más lejos de la realidad. Parafraseando a Enric Satué, en el devenir histórico del conjunto de tipologías que constituyen el diseño gráfico -la edición, la publicidad y la identidad- existen periodos excepcionales fuertemente marcados por alguna de ellas en particular ${ }^{62}$. La socialización de la cultura no podría plantearse sin la invención del diseño gráfico. En este sentido la epigrafía, además de ser un medio de información, es un arte visual que le es conferido a través de sus caracteres funcionales. Denominamos caracteres funcionales «aquellos que confieren a la inscripción su especial carácter de medio de comunicación publicitaria» ${ }^{63}$. En efecto, son recursos que emplea el autor para dar una mayor publicidad al mensaje, de los cuales depende su propia eficacia comunicativa ${ }^{64}$. Los caracteres funcionales son el elemento de carácter físico que van a afectar principalmente a los componentes externos del epígrafe, esto es, a la escritura y el soporte. Navascués lo denominó como el «medio expresivo» ${ }^{65}$ del epígrafe a través del cual el mensaje logra mayor impacto visual al público. Su efectividad depende de la capacidad del rogatario para ejecutar el letrero. Son diversos los elementos a tener en cuenta: el soporte, el alfabeto, y la impaginatio. Este último adquiere

59. Favreau, R., Michaud, J., Mora, B. (eds) Corpus des Inscriptions de la France Médiévale, (CIFM) La ville de Vienne en Dauphiné, vol. 15, Poitiers 2000, Lamina 74.

6o. CIFM, 15, Lam. 79-80

61. CIFM, 15, Lam. 33.

62. Cf. SATUÉ, Enric, El diseño gráfico. Desde los orígenes hasta nuestros días, Alianza Forma, Madrid, 2004, p. 31.

63. Cf. García Lobo, V., «La epigrafía medieval: cuestiones de método», Centenario de la Cátedra de «Epigrafía y Numismática» Universidad Complutense de Madrid 1900/01-2000/01, Madrid 2001, pp. 77-119, concretamente, pp. 85-8799-100.

64. Pereira, Irene, «Espacio y comunicación: una aproximación a los caracteres funcionales de la epigrafía medieval», en Actas del I Congreso de investigadores noveles en Ciencias Documentales: Funciones y prácticas de la escritura, Madrid, 2013, Madrid, Universidad Complutense de Madrid, 2013, pp. 179-186. Concretamente p. 181.

65. NAVASCuÉs, Joaquín María, «Concepto de epigrafía, Consideraciones sobra la necesidad de su ampliación», en Discursos de la Real Academia de la Historia, Madrid 1953, p. 67. 
una importancia especial en el conjunto rotense. Impaginatio $^{66}$ es el proceso técnico de la génesis de un epígrafe, la estructuración de la página epigráfica, la delimitación del espacio destinado al texto y la colocación de las líneas guía que luego sirven de apoyo a la escritura. En esta fase se determina el diseño general y el acabado del epígrafe. Buen ejemplo de este proceso técnico lo hallamos en las inscripciones próximas a la sala capitular donde se muestra un claro paralelismo con el libro.

La distribución del texto sobre el campo epigráfico recuerda las páginas de un códice y le confiere al conjunto epigráfico una imagen peculiar y diferente ${ }^{67}$. En algún caso, el lapicida se inspira en el mundo librario, de manera que nos muestra el campo epigráfico dividido en dos

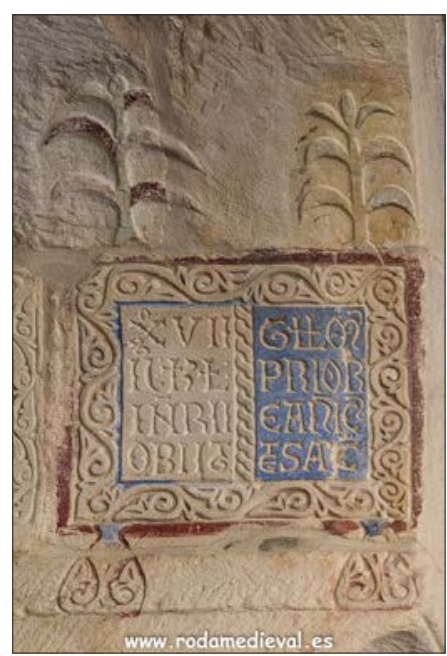

FIGURA 14. N ${ }^{\circ} 255$ SALA CAPITULAR subcampos como un libro abierto con anotaciones en el reverso y en el anverso (fig. I4). Otras inscripciones, no obstante, se inspiran más en los primeros folios de los grandes libros con decoración que invade toda la superficie (fig. I5a I5b).

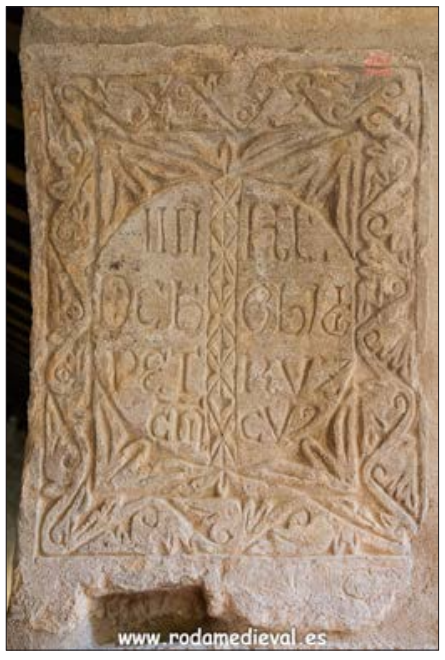

FIGURA 15A. N 245 MEDIADOS XIII

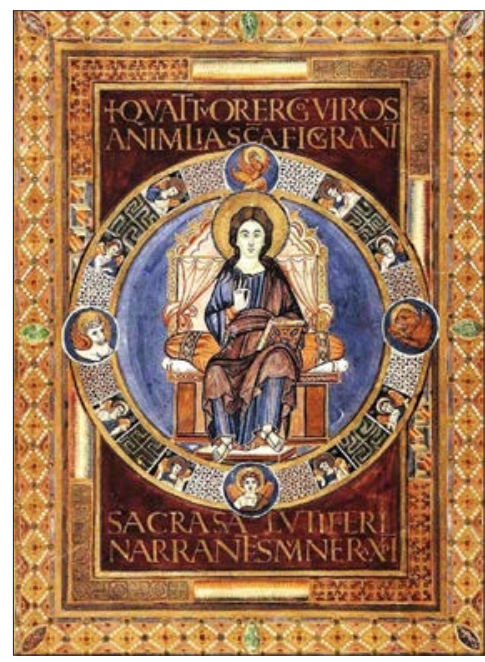

FIGURA 15B. BIBLIA DE LORSCH

66. Adoptamos este término de la codicología, como las técnicas de rayado y de impaginación, Cf. E. RuIz, Introducción a la Codicología, Madrid, 2002, pp. 179-232. En Epigrafía Medieval destacamos el monográfico dedicado a este proceso técnico por investigadores internacionales ya citado anteriormente V. GARCíA LOBO Y M.E. MARTíN LÓPEZ (Coord.), Impaginatio en las inscripciones medievales, León, 2011.

67. Sobre estas transferencias del códice, Impaginatio, eds. E. Martín López- V. García Lobo, León, 2011. 
Observamos cómo el lapicida combina éstos con otros recursos que confieren armonía al conjunto y sirven como llamada de atención sobre el texto. Éstos son la cuidada grafía ${ }^{68}$, el módulo mayúsculo de las letras, el mayor peso de la escritura, propio de la gótica, con un contraste entre trazos gruesos y finos, que hemos analizado, añadiendo el color como finalidad estética. No es casual que buena parte de las inscripciones así diseñadas se encuentren en la actualidad concretadas en un mismo espacio, el acceso a la sala capitular. Memoria pública y perdurable es la finalidad principal de la inscripción a la vez que su aspecto produce una veneración por lo escrito en ella ${ }^{69}$.

\section{VI.1. DECORACIÓN Y ORNAMENTACIÓN}

La impaginación desde los primeros letreros delimita la caja de escritura mediante doble línea marginal. Este espacio delimitado por las líneas marginales será aprovechado para una decoración incipiente, de puntos y rayas, para ir ensanchándose a mediados de siglo y ser objeto de una decoración más cuidada. Las distintas fases de ejecución de estos elementos ornamentales se observan en algunas piezas inacabadas (fig.I6).

Incorporar elementos decorativos puede tener no solo una función estética sino también simbólica, fruto de una supervivencia clásica que arranca del arte griego y romano. A través de estos elementos decorativos el cristianismo expone sus conceptos religiosos y su fe. En las inscripciones de Roda la decoración es mayoritariamente vegetal, con hojas exuberantes cuya naturaleza debemos adivinar. Solo unas pocas inscripciones son ornamentadas con decoración de $\operatorname{soga}^{70}$. Se hace difícil su identificación, no obstante, dentro de la variedad de vegetales empleados en la decoración de objetos y lugares religiosos podemos reducir el campo a dos posibilidades. Debido a la exuberancia de las hojas podríamos suponer que se trata de hojas de acanto que tanto juego han dado en la ornamentación desde Roma y durante toda la edad media, y a las cuales se les atribuye un hipotético

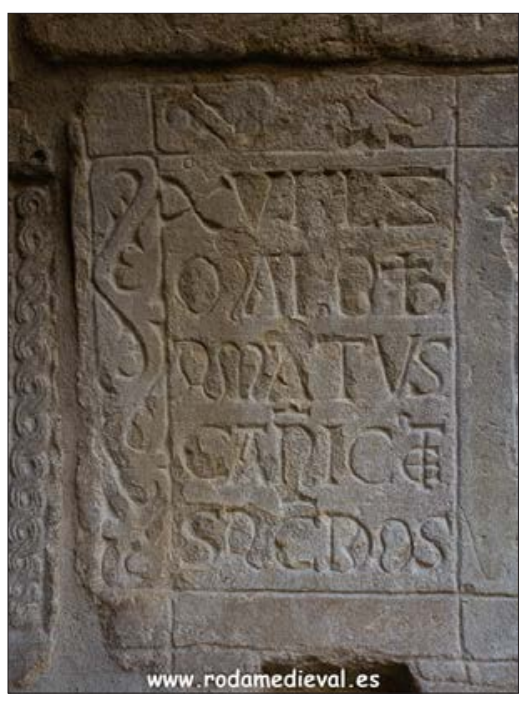

FIGURA 16. N ${ }^{0} 147$, PANDA SUR

68. Será la escritura la que se convierta en un sistema visual con una función figurativa Cf. A. PETRucCl, Alfabetismo, escritura, sociedad, Barcelona, 1999, pp. 171-180.

69. Pereira, «Espacio y comunicación», p. 183.

70. $N^{\circ} 90$ en la panda este. Óbito de Arnaldo, el 13 de enero. 
simbolismo de inmortalidad ${ }^{71}$. Otra opción sería las hojas de hiedra cuya presencia se rastrea en el arte cristiano desde el siglo V. Suele ir decorando sepulcros desde el mundo visigodo hasta los sarcófagos merovingios y carolingios y tiene igualmente un simbolismo de eternidad ${ }^{72}$. En el medievo hispano estamos más habituados a su imagen en forma de corazón cerrando o rematando el texto de inscripciones visigodas y después en las medievales, como en el altar central de San Miguel de Escalada ${ }^{73}$.

\section{CONCLUSIONES}

La antigua catedral episcopal de San Vicente de Roda conserva su necrologio escrito en piedra constituido por más de doscientas inscripciones, que le convierte en el más importante referente epigráfico necrológico europeo. Un relieve, si cabe, aún mayor si tenemos en cuenta que es el único testimonio escrito que queda del original obituario en pergamino, hoy desaparecido. Para la realización de esta empresa el cabildo contará con los medios a su alcance, a través de los profesionales de la escritura de su activo scriptorium. Esto supone una actividad lapidaria con un taller epigráfico profesional permanente, formado o dirigido, posiblemente, por un canónigo o eclesiástico. La larga actividad del personal indicaría la pertenencia o vinculación de estos profesionales a la comunidad, aunque desconocemos su condición (canónigos, socios, presbíteros). El traslado del obituario a piedra se inicia en el primer tercio del siglo XIll. El número de lapicidas que trabajan en estos años queda aún por determinar de forma exhaustiva en un análisis que aún no ha finalizado, aunque, de momento, los estudios paleográficos realizados nos permiten determinar ocho lapicidas. La actividad cesa definitivamente a finales, entre I370-I390 con dos inscripciones, ejecutadas por un solo lapicida, que manifiestan la evolución final de la escritura gótica a formas estrechas, alargadas y de trazos cerrados que dificulta notablemente su lectura. Estas piezas marcan el final de la existencia conocida del taller epigráfico rotense. Entre los distintos lapicidas que trabajan en el claustro destaca el llamado maestro de Roda (I232I24I) por su diseño gráfico y la peculiaridad de sus letreros, que confieren a sus inscripciones un particularismo visual y estético poco común. El taller muestra en su ejecución una estrecha vinculación y formación en el scriptorium de la canónica.

71. JaLABERT, La Flore Sculptée des monuments du Moyen Acie en France, Paris, 1965. pág. 14, atribuyendo el acanto espinoso a los griegos y el acanto molle a los romanos. No obstante, existe un doble simbolismo, el griego, que le atribuye la inmortalidad, el cristiano, que le atribuye la virginidad, los sufrimientos corporales y espirituales, así como la duda. Parece que en este contexto triunfa el primero, pp. 81-82

72. Sobre el simbolismo vegetal contamos con el estudio de La decoración vegetal en el arte español de la alta edad media: su simbolismo, Tesis doctoral leída en 1992 por Ana María Quiñones en la Universidad Complutense.

73. De marcada tradición hispano romana es la decoración del altar central de Escalada, mostrando la pervivencia de las formas y la estética romana y visigoda. Cf. M.E. Martín López, «La huella de la antigüedad clásica en las inscripciones medievales», en El mundo antiguo visto por el hombre medieval: II Jornadas de estudios medievales, Instituto de Estudios medievales, León 2013. 
Se transfieren así elementos gráficos y decorativos propios de los documentos y de los libros. Por otra parte, hallamos paralelismos gráficos con las inscripciones del sur de Francia. La estética del conjunto funerario de Roda es una manifestación más de la importancia que la liturgia de difuntos tenía en las comunidades religiosas en los siglos XIII y XIV, creando un vínculo de veneración de los vivos hacia los difuntos a través de su memoria pública y perdurable. 


\section{BIBLIOGRAFÍA}

Agustín de Hipona, De la piedad con los difuntos, en Obras completas de San Agustìn, BAC, vol. XL, Madrid I994.

ALFÖLDY, Géza, «Augusto e le iscrizioni: tradizione ed innovazione. La nascita dell'epigrafi a imperiale», Scienze dell'Antichità. Storia, Archeologia, Antropologia, 5, I99I, pp. 573-60o

BARroca, Mario Jorge, Epigrafía medieval portuguesa 862-I422, Lisboa, 2000.

BATELli, Iulio, Lezioni di paleografía, Librería editrice Vaticana, I949.

Carmona Moreno, Félix, «Los difuntos en las Constituciones y Rituales de los agustinos. Lugar de enterramiento y libros de difuntos», en El mundo de los difuntos: culto, cofradías $y$ tradiciones, San Lorenzo del Escorial 20I4, pp. 68I-698.

DE RUBEıs, Flavia, «La capitale romanica e la gótica epigrafia: una relazione difficile», en Las inscripciones góticas, II Coloquio Internacional de Epigrafía Medieval, León, 2010, pp. 185-202.

Debiais, Vincent, Messages de pierre. La lecture des inscriptions dans la communication médiévale (XIII ${ }^{e}$-XIV siècle), Turnhout, Brepols, 2009.

Donati, Angela, Epigrafia romana. La comunicazione nell'antichità, Bolonia, 2002.

Dubois, Jacques, Les martyrologes du Moyen âge latín, Tipologie des sources du Moyen Agen occidental, 26, Turnhout, Brepols, 1978.

Durán Gudiol, Antonio, «Las inscripciones medievales de la provincia de Huesca», en Estudios de Edad Media de la Corona de Aragón, 8, I967, pp. 45-I09.

Favreau, Robert - Michaud, Jean - Mora, Bernardette, Corpus des Inscriptions de la France Medievale, (CIFM) La ville de Vienne en Dauphiné, vol. I5, Poitiers, 2000.

FAVREAU, Robert, «Functions des inscriptions», en Études d'épigraphie medieval, Limoges, I995 Pulim, pp. I55-205.

García Fernández, Patricio, «La memoria epigráfica del monasterio de Santa Cristina de Ribas de Sil, sus inscripciones medievales», en Boletín Auriense, 33, 2003, pp. 185-208.

García Lobo, V. - Cavero Domínguez, G. (eds), San Miguel de Escalada, eds. García Lobo y G. Cavero, León, 2013.

García Lobo, V. - Martín López, M.E. (Coords.), Impaginatio en las inscripciones medievales, León, 2011.

García Lobo, Vicente, La colegiata de Santa Maria de Arbas, León, I990.

García LoBo, Vicente, «La epigafía del claustro de Silos», en IX Centenario de la consagración de la iglesia y claustro (Io88-I988), Studia Silensia Maior, I, Abadía de Silos-Burgos, I990, pp. 85-98.

García Lobo, Vicente, Las inscripciones de San Miguel de Escalada, El Albir, Barcelona, I982.

García Lobo, Vicente, Los medios de comunicación social en la Edad Media, Universidad de León, León, I99I.

García Lobo, Vicente. «La epigrafía medieval: cuestiones de método», Centenario de la Cátedra de «Epigrafía y Numismática» Universidad Complutense de Madrid I900/oI2000/OI, Madrid, 200I, pp. 77-II9.

García Morilla, Alejandro, «La impaginatio en las inscripciones del románico burgales», en Impaginatio en las inscripciones medievales, León, 20II, pp. 215-229.

GARCía Morilla, Alejandro, «De la funcionalidad en las inscripciones. El caso del monasterio de Santiago de Peñalba (León)», en San Miguel de Escalada (9I3-20I3), León, 20I3, pp. 273-293.

Giove MARCHIOLI, Nicoletta, «L' impossibilità di essere autonoma donne e famiglia nelle fonti epigrafiche tardomedievali», Archeologia Medievale, XXXVIII, 20II, pp. I9-32. 
Gómez Moreno, Manuel, Discurso de D. Manuel Gómez-Moreno y Martínez, en Navascués y de Juan, Joaquín María, El concepto de la Epigrafía. Consideraciones sobre la necesidad de su ampliación, Madrid, Real Academia de la Historia, Madrid, I953.

Gramigni, Tomasso, Iscrizioni medievali nel territorio fiorentino fino al XIII secolo, Firenze press, 2012.

GraU Quiroga, Esther, Roda de Isabena en los siglos X al XIII. La documentación episcopal y del cabildo catedralicio, Institución Fernando el Católico, Zaragoza, 20 Io.

Gudiol, Joseph, «El necrologi de l'iglesia de Roda», en Anuari de l'institut d'estudis catalans, I907, pp. 19-29.

Gutiérrez Álvarez, Maximino, Corpus Inscriptionum Hispaniae Mediaevalium, Zamora, I.2, Brepols, Turnhout-León, I995.

Herrero Jiménez, Mauricio, « La muerte en los obituarios medievales », en IX Jornadas científicas sobre Documentación: la muerte y sus testimonios escritos, Universidad Complutense, Madrid, 20II, pp. I99-220.

Herrero Jiménez, Mauricio, Colección documental del archivo de la catedral de León. X. Los obituarios de la catedral de León, León, 1994.

Huyguebaert, Nicola, Les documents nécrologiques, Tipologie des sources au Moyen Age Occidental, Turnhout, 1972.

Iogna Pratt, D., «Los muertos en la contabilidad eclesial de los monjes cluniacenses», en Little L.K. y Rosenwein B. (ed) La Edad Media a debate, Madrid, 2003, pp. 52I-55I.

Jalabert, Denise, La Flore Sculptée des monuments du Moyen Acie en France, Paris, I.965.

$\mathrm{KoCH}$, Walter, «The gothic script in inscriptions. Origin, characteristics and evolution», en Las inscripciones góticas, II Coloquio Internacional de Epigrafía Medieval, León, 20Io, pp. 9-29.

LeClercQ, Henri, « Obituaire », en Dictionnaire d'Archéologie Chrétien et Liturgie, I2-2. París, I936, cols. I834-I857.

Lemaître, Jean Loup, Un livre vivant, l'obituaire, en GLEnisson, J (dir.), Le livre au Moyen Âge. París: CNRS, I988.

Marín Martínez, Tomás, Los códices de Santo Martino. Singularidades paleográficas, Santo Martino de León. Ponencias del I Congreso Internacional sobre Santo Martino en el VIII centenario de su obra literaria II85-I985, León I987.

MARTí DE Viciana, Libro tercero de la crónica de la ínclita y coronada ciudad de Valencia y de su reino, a cargo de Joan Iborra, Valencia 2002,

MARTín López, M ${ }^{\text {a }}$ Encarnación, «La escritura gótica epigráfica», en Paleografía II Las escrituras góticas desde I250 hasta la imprenta. V Jornadas de la Sociedad Española de Ciencias y Técnicas Historiográficas, Oviedo 2007.

Martín López, Ma Encarnación», Las inscripciones de San Miguel de Escalada. Nueva lectura», en San Miguel de Escalada (913-2013), Universidad de León, 2013.

MARTín López, Ma Encarnación, «La huella de la antigüedad clásica en las inscripciones medievales», en El mundo antiguo visto por el hombre medieval: II Jornadas de estudios medievales, Instituto de Estudios medievales, León, 2013.

MatToso, José (dir.), O reino dos mortos na Idade Media, Lisboa, I996, donde publica dos artículos sobre el culto a los difuntos.

Mitre, Emilio, «El sentido medieval de la muerte», en Anuario de Estudios Medievales, I6,I986, pp. 62I-663.

Molina, Francisco Javier, Corpus Inscriptionum Hispaniae Mediaevalium. vol. 3. Valladolid, Instituto de Estudios Medievales, León.

Molinier, August, Les obituaires français au Moyen Âge. París, I89o. 
NAVASCUÉs, Joaquín María, «Concepto de epigrafía, Consideraciones sobra la necesidad de su ampliación», en Discursos de la Real Academia de la Historia, Madrid I953.

Orlandis, José, La vida en tiempos de los godos, Madrid, I99I.

PEREIRA, Irene, «Espacio y comunicación: una aproximación a los caracteres funcionales de la epigrafía medieval», en Actas del I Congreso de investigadores noveles en Ciencias Documentales: Funciones y prácticas de la escritura (Madrid, 2013), Madrid, Universidad Complutense de Madrid, 20I3, pp. I79-I86.

Petruccl, Armando, Alfabetismo, escritura, sociedad, Barcelona, I999.

Petrucci, Armando, La scrittura: ideologia e rappresentazione, Turín, I986

PONS CORTÉs, A. «Necrologios y obituarios medievales en la Península Ibérica y su utilización como fuente para la historia de la arquitectura», en Medievalia. Revista d'estudis medievals, 20/I 2017, pp. I97-223.

QUiÑONES, Ana $\mathrm{M}^{\mathrm{a}}$, La decoración vegetal en el arte español de la alta edad media: su simbolismo, Tesis doctoral leída en 1992.

Reglero, Carlos, «El necrologio-obituario de San Zoilo de Carrión», en Alma Littera, Valladolid, 20I4, pp. 525-533.

Ruiz Asencio, José Manuel, Colección documental del archivo de la catedral de León, VIII (I230-I269), León, I993.

Ruiz, Elisa, Introducción a la Codicología, Madrid, 2002.

SANTIAGO, Javier de, «Oraciones por la salvación del alma. El obituario en piedra del monasterio de Sant Pau de Camp de Barcelona», en Anuario de Estudios medievales, 46/2, 2016, pp. 939-973.

SATUÉ, Enric, El diseño gráfico. Desde los orígenes hasta nuestros días, Alianza Forma, Madrid, 2004.

Serna Serna, Sonia, Los obituarios de la catedral de Burgos, León, 2007.

SusinI, Giancarlo, «Le scritture esposte», en Lo spazio letterario di Roma antica. 2. La circolazione del testo, Roma, Salerno, I989, pp. 27I-305.

Trenchs Òdena, José, «El necrologio-obituario de la catedral de Cuenca», en Anuario de Estudios Medievales, I2 (I982), pp. 34I-380.

Ubieto Arteta, Antonio, El obituario de la catedral de Pamplona, Instituto Príncipe de Viana, Pamplona, I954. 
Calidad de Revistas

Científicas Españolas

FECYT |
SERIE III HISTORIA MEDIEVAL

REVISTA DE LA FACULTAD DE GEOGRAFÍA E HISTORIA
AÑO 2020

ISSN: 0214-9745

E-ISSN 2340-1362

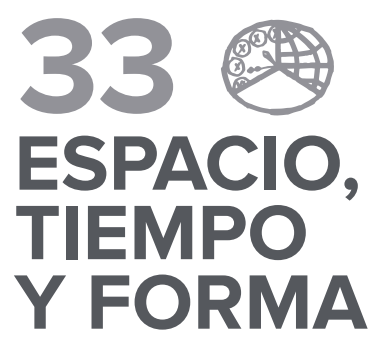

\section{Artículos · Articles}

7 FREDERIC APARISI ROMERO

El cultivo y procesado del lino en el Reino de Valencia (ss. XIII-XVII)

13 ADRIÁN CALONGE MIRANDA

El mantenimiento del entramado viario romano en época medieval en La Rioja. Algunos casos de estudio

\section{Miguel Calleja Puerta}

Notarios públicos entre dos reinos. Apuntes diplomáticos sobre documentos notariales castellanos en el Arquivo Distrital de Braga

\section{Xavier Casassas Canals}

Las 'aqida-s entre los musulmanes castellanos y aragoneses de época mudéjar y morisca: Las 'aqida-s de lbn Abi Zayd Al-Qayrawāni (s. X), Ibn Tümart (s. XII) e Isa de Jebir (s. XV)

\section{ARCADIO DEL CASTILLO}

Sobre el Códice Alcobacense de Vaseo y los Annales Portugalenses Veteres: Continuidad del reino visigodo de Toledo

\section{Paula Castillo}

Las formas de la violencia entre frailes. El testimonio de Fray Ubertino de Casale

\section{María Eugenia Contreras JimÉnEZ}

La memoria del linaje Arias Dávila en la cofradía y hospital de San Cosme y San Damián de Valladolid (siglos XV a XVII)

193 María Francisca García Alcázar y María Ángeles Martín
Romera Entre servicio regio y estrategia personal: Los Continos de Valladolid (1480-1525)

\section{César García de Castro Valdés y josé Antonio Valdés
Gallego}

Las inscripciones perdidas de la basílica altomedieval de San Salvador de Oviedo

\section{María José Lop OtÍN}

Hay tal número de clérigos que causa asombro. La clerecía de Toledo a fines de la Edad Media

\section{CORINA LUCHÍA}

Por que los montes de esta villa se conserben, e no se disipen como al presente estan: La regulación de los recursos forestales en la Corona de Castilla (siglos XIV-XVI)
333 María Encarnación Martín López

Las inscripciones medievales del claustro de la catedral de Roda de Isábena (Huesca). Aproximación a su taller lapidario

\section{ISABEL MONTES ROMERO-CAMACHO}

Los archivos catedralicios y su importancia para los estudios prosopográficos. El deán Don Aparicio Sánchez, en el Archivo de la Catedral de Sevilla

\subsection{Gonzalo Oliva Manso}

La moneda en Castilla y León (1265-1284). Alfonso X, un adelantado a su tiempo.

4.73 Mariana Valeria Parma

Entre los signos del cielo y las voces de los hombres: La visión medieval del cielo y su representación apocalíptica

\section{Milagros Plaza Pedroche \\ Los maestres santiaguistas y su designación regia durante el} reinado de Juan I de Trastámara (1379-1390): La legitimación del proceso

521 Juan A. Prieto Sayagués

La profesión de las élites castellanas en los monasterios y conventos durante la Baja Edad Media

\section{ENRIQUE JOSÉ RUIZ PILARES}

La funcionalidad social de los inmuebles urbanos de las élites dirigentes bajomedievales: Reflexiones a partir de un caso de estudio (Jerez de la Frontera, España)

\section{Gilberto SORIANO Calvo}

Influencia de las redes nobiliarias en la expansión cristiana del siglo XII. El caso de Soria

Mohammed S. TawfiQ, AlmudenaArizaArmada, Atef Mansour Mohammad, Ahmed Ameen y Mervat Abd EL-HadyAbdEL-Latif A Historical and Numismatic Study of the Dinars of the Ghaznavid Sultan Mahmūd B. Sabuktakin at Nishapur

653 JOSÉ LUIS DE VILLAR IGLESIAS

Los aspectos económicos en la Batalla por el Magreb entre omeyas y fāțimíes: El control del acceso al oro del Sudán Occidental 


\section{3}

\section{ESPACIO,}

\section{TIEMPO}

Y FORMA

UกED

SERIE III HISTORIA MEDIEVAL

REVISTA DE LA FACULTAD DE GEOGRAFÍA E HISTORIA

\section{Libros · Books}

679 Bello León, Juan Manuel y ORTEgo Rico, Pablo, Los agentes fiscales en la Andalucía Atlántica a finales de la Edad Media: Materiales de trabajo y propuesta de estudio (ANA MARÍA RIVERA MEDINA)

683 Calleja Puerta, Miguel y Domínguez Guerrero, María Luisa (eds.), Escritura, notariado y espacio urbano en la Corona de Castilla y Portugal (siglos XII-XVII) (PALOMA CUENCA MuÑoz)

687 CASADO ALONSO, Hilario (coord.), Comercio, finanzas $y$ fiscalidad en Castilla (siglos XV-XVI) (ANA MARía RIVERA MEdINA)

691 Castro Correa, Ainoa y Rodríguez Sánchez, Manuel, Colección diplomática altomedieval de Galicia II. Documentación en escritura visigótica de la sede lucense (PALOMA CUENCA MUÑOZ)

695 García Fernández, Ernesto, García-Gómez, Ismael, Rodríguez FERNÁNDEZ, José, Urbanismo, patrimonio, riqueza y poder en Vitoria-Gasteiz a fines de la Edad Media e inicios de la Edad Moderna (ENRIQUE CANTERA MONTENEGRO)

699 LADERO QUESADA, Miguel Ángel, Ciudades de la España medieval. Introducción a su estudio (GISELA CORONADO SCHWINDT)

705 LADERo Quesada, Miguel Ángel, Los últimos años de Fernando el Católico 1505-1517 (CARLOS BARQuero GoÑI)

707 Martín GutiérRez, Emilio y Ruiz Pilares, Enrique José, El viñedo en Jerez durante el siglo XV. Un mercado de trabajo en torno al vino (ANa María Rivera MEDINA)

711 MONSALVO ANTÓN, José María, La construcción del poder real en la monarquía castellana (siglos XI-XV) (MARÍA Jesús FUENTE)

715 Pérez Rodríguez, Francisco Javier, Los monasterios del Reino de Galicia entre 1075 y 1540: De la reforma gregoriana a la observante (EnRIQue CANTERA Montenegro)

717 REIXACH SALA, Albert, Finances públiques i mobilitat social a la Catalunya de la Baixa Edat Mitjana. Girona, 1340-1440 (JuLIÁN DONADO VARA)

721 SÁNCHEZ SÁNCHEZ, Xosé M., Iglesia, mentalidad y vida cotidiana en la Compostela medieval (ENRIQUe CANTERA MONTENEGRO)

725 Val Valdivieso, M. ${ }^{a}$ Isabel del, Martín Cea y Juan Carlos, CARVAJAL de La Vega, David (coords.), Expresiones del poder en la Edad Media. Homenaje al profesor Juan Antonio Bonachía Hernando (José RAmón Díaz de DURANA ORTIZ de URBINA) 